Purdue University Purdue e-Pubs

$11-1-2006$

\title{
Advances in mesoscale thermal management technologies for microelectronics
}

Suresh Garimella

School of Mechanical Engineering, sureshg@purdue.edu

Follow this and additional works at: http://docs.lib.purdue.edu/nanodocs

Garimella, Suresh, "Advances in mesoscale thermal management technologies for microelectronics" (2006). Other Nanotechnology Publications. Paper 15.

http://docs.lib.purdue.edu/nanodocs/15

This document has been made available through Purdue e-Pubs, a service of the Purdue University Libraries. Please contact epubs@purdue.edu for additional information. 


\title{
Advances in mesoscale thermal management technologies for microelectronics
}

\author{
Suresh V. Garimella* \\ Cooling Technologies Research Center, School of Mechanical Engineering, Purdue University, West Lafayette, Indiana 47907-2088 USA
}

Received 25 November 2004; received in revised form 11 May 2005; accepted 22 July 2005

Available online 19 September 2005

\begin{abstract}
This paper presents recent advances in a number of novel, high-performance cooling techniques for emerging electronics applications. Critical enabling thermal management technologies covered include microchannel transport and micropumps, jet impingement, miniature flat heat pipes, transient phase change energy storage systems, piezoelectric fans, and prediction of interface contact conductance.
\end{abstract}

(C) 2005 Elsevier Ltd. All rights reserved.

Keywords: Mesoscale; Thermal management; Microelctronics

\section{Introduction}

The cooling needs of the electronics and computer industries for high-end applications have surpassed the capabilities of conventional methodologies such as natural convection or fan-blown air cooling. Even applications with lower heat dissipation levels can pose severe challenges due to space, weight, power consumption, noise level, or other contraints. A host of new methodologies have been proposed over the last decade to cope with this increasing demand. There are now several journals solely dedicated to the reporting of work in this field, as well many books summarizing the state of the art. This paper discusses some of these high-performance cooling techniques, including microchannel heat sinks and micropumps, jet impingement, flat heat pipes, phase change energy storage and contact conductance. Novel concepts including integrated liquid microchannel cooling systems, microscale ion-driven airflow, and piezoelectric fans are also presented.

\section{Microchannel heat sinks and micropumps}

The use of microchannels for high power-density electronics cooling has been widely studied. Along with

\footnotetext{
${ }^{*}$ Corresponding author. Tel.: + 1765494 5621; fax: + 17654940539 .

E-mail address: sureshg@ecn.purdue.edu.
}

providing very high heat transfer coefficients, microchannel heat sinks are very compact in size, which enhances their suitability to electronics cooling.

The microscale dimensions of these channels calls for great care in experimental characterization. In addition, the behavior of microchannels can be different from the corresponding macroscale channels, since the various forces affecting flow and heat transfer scale differently, and take on different levels of dominance as the dimensions are reduced.

Various aspects of transport in microchannels relevant to electronics cooling applications are discussed here. The results of studies in the literature on fluid flow and heat transfer through microchannels are first compared and inconsistencies identified. Fluid flow and heat transfer experiments conducted on channels of hydraulic diameter ranging from 250 to $1000 \mu \mathrm{m}$ are then presented, and results from these experiments compared to predictions from conventional correlations. The pumping requirements of microchannel heat sinks are derived, along with a method to assess the suitability of a given pump to a microchannel heat sink application. Optimization of microchannel dimensions for a specified thermal load to minimize the pumping requirements is also discussed. Various micropumps presented in the literature are also briefly reviewed in terms of their suitability to electronics cooling. 


\subsection{Review of past studies}

A comprehensive review of studies in the literature on fluid flow and heat transfer through microchannels is available in [1]. The emphasis of the review was on experimental results obtained for micro- and mini-channels and tubes. Investigations of boiling and two-phase flows in small channels and tubes, gas flow in microchannels, analytical studies on microchannel flows, and design and testing of microchannel heat sinks for electronics cooling were also reviewed. Results for single-phase conditions, quantified in terms of friction factor and Reynolds number for fluid flow and in terms of Nusselt number and Reynolds number for heat transfer, were compared to predictions from conventional correlations both in laminar and turbulent regimes in an earlier paper by Sobhan and Garimella [2].

The friction constant $f R e$ and Nusselt number are plotted against Reynolds number in Figs. 1 and 2 from experimental studies in the literature on a $\log -\log$ scale [3-11]; the laminar regime is considered in part (a) of each figure, while the turbulent regime is considered in part (b). The experimental results are compared to the following conventional correlations: For the friction constant, $f R e=$ 64 for circular tubes and $f R e=57$ for square channels, both for laminar flow, and the Blasius correlation, $f R e^{-0.182}=0.14$, for turbulent flow; for the Nusselt number, the theoretical predictions in the laminar regime are from $N u=1.86(\operatorname{Re} \operatorname{Pr})^{0.33}(D / L)^{0.33}$ (with $L=50 \mathrm{~mm}$ and $D=0.24 \mathrm{~mm}$ to obtain representative values), while the Dittus-Boelter correlation is used for predictions in the turbulent regime.

It is clear from Figs. 1 and 2 that there is little agreement between the results from different investigators for either fluid flow or heat transfer in both laminar and turbulent regimes. Most of the experimental results deviate from the theoretical predictions which assume macroscale behavior. The measurements lie both above and below the predictions, and also show different trends of variation relative to the conventional predictions in the laminar and turbulent regimes. In addition, transition from the laminar to turbulent regimes appears to occur at lower Reynolds numbers in many of the experimental studies relative to expectations from conventional analysis. These results have been cited to support the existence of differences in the physics at macro- and micro- length scales.

In view of the wide disparity in the literature on pressure drop and heat transfer in microchannels, carefully designed experiments were performed to understand the reasons for these discrepancies, as described below.

\subsection{Single-phase flow and heat transfer}

An experimental facility was designed to conduct fluid flow and heat transfer experiments in microchannels with hydraulic diameter ranging from 250 to $1000 \mu \mathrm{m}$. The aim of the experiments was to carefully analyze flow and heat
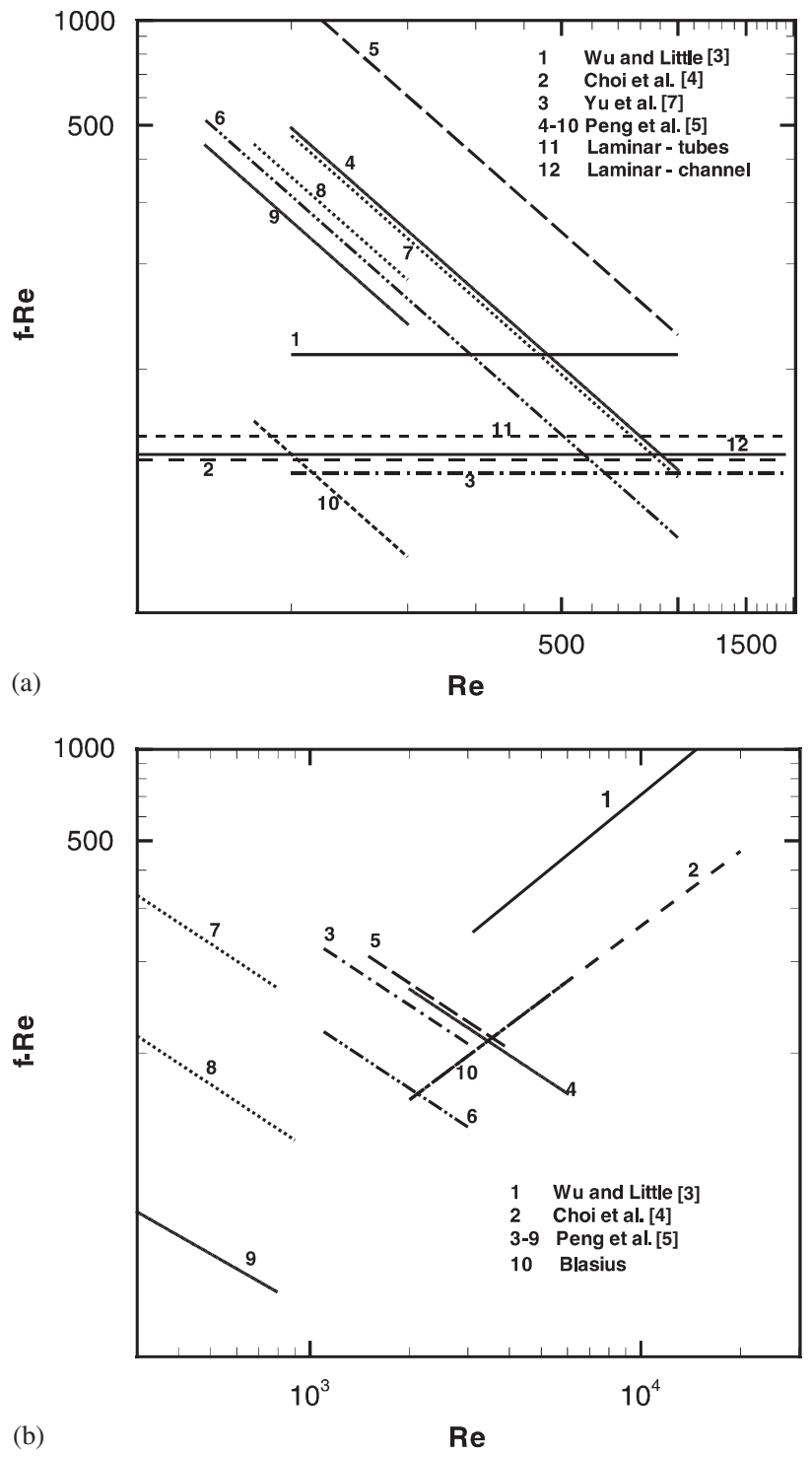

Fig. 1. Friction factor from experimental results and theoretical predictions for (a) laminar, and (b) turbulent flow [2].

transfer behavior in microchannels, verify the Reynolds numbers for transition from laminar to turbulent flow, and to assess the validity of the conventional correlations in predicting these characteristics.

Two different approaches were used in the fluid flow experiments with short and long microchannels, separately. The pressure drop measurements obtained from the short channels included pressure losses due to the sudden contraction at the inlet and the expansion at the outlet of the channels. In contrast, pressure drops obtained from the long channels included no additional losses. Details of the experimental setup and the uncertainty analysis for these experiments are described in [12]. Typical experimental results for friction factor $f$ are plotted against Reynolds number and compared to the predictions from correlations in Fig. 3(a) for long channels and Fig. 3(b) for short channels, respectively. The pressure losses due to the 

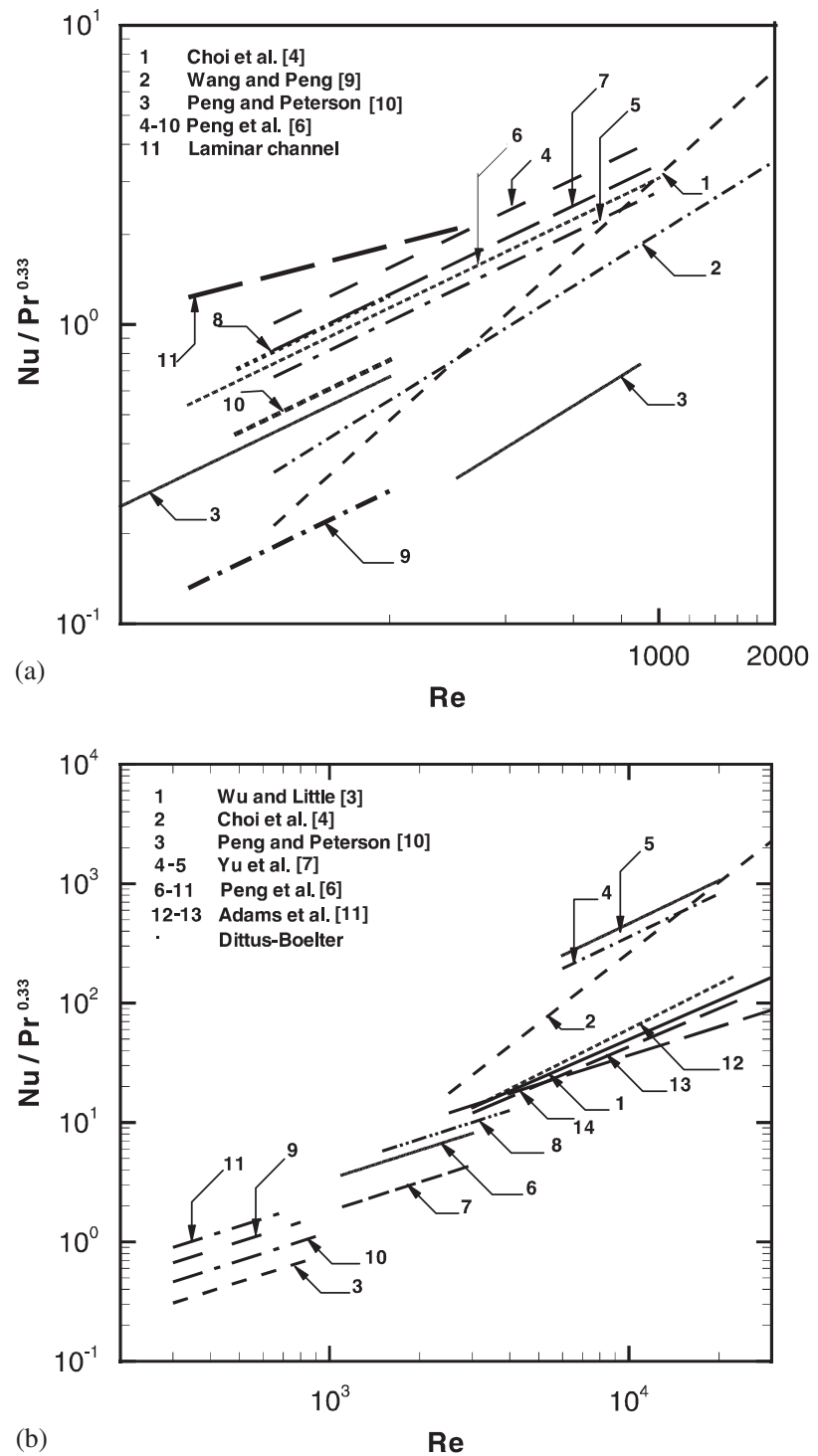

Fig. 2. Heat transfer from experimental results and theoretical predictions for (a) laminar, and (b) turbulent flow [2].

entrance and exit have been subtracted from the measured values in interpreting the short channel data.

The figures show clearly that the experimental results match the predictions quite well. It may be noted that the experimental friction factors start to deviate from the laminar predictions at $R e \approx 2000$, indicating the onset of transition. This again indicates that the hydrodynamic behavior of the microchannels is not different from that of conventional channels in terms of transition.

The heat transfer experiments were performed using a copper heat sink with microchannels of hydraulic diameter ranging from 318 to $902 \mu \mathrm{m}$, as described in [13]. The experimental results are compared in Fig. 4(a) through 4(c) to theoretical predictions and empirical correlations for different thermal and hydrodynamic boundary conditions, including simultaneously developing laminar flow, ther-
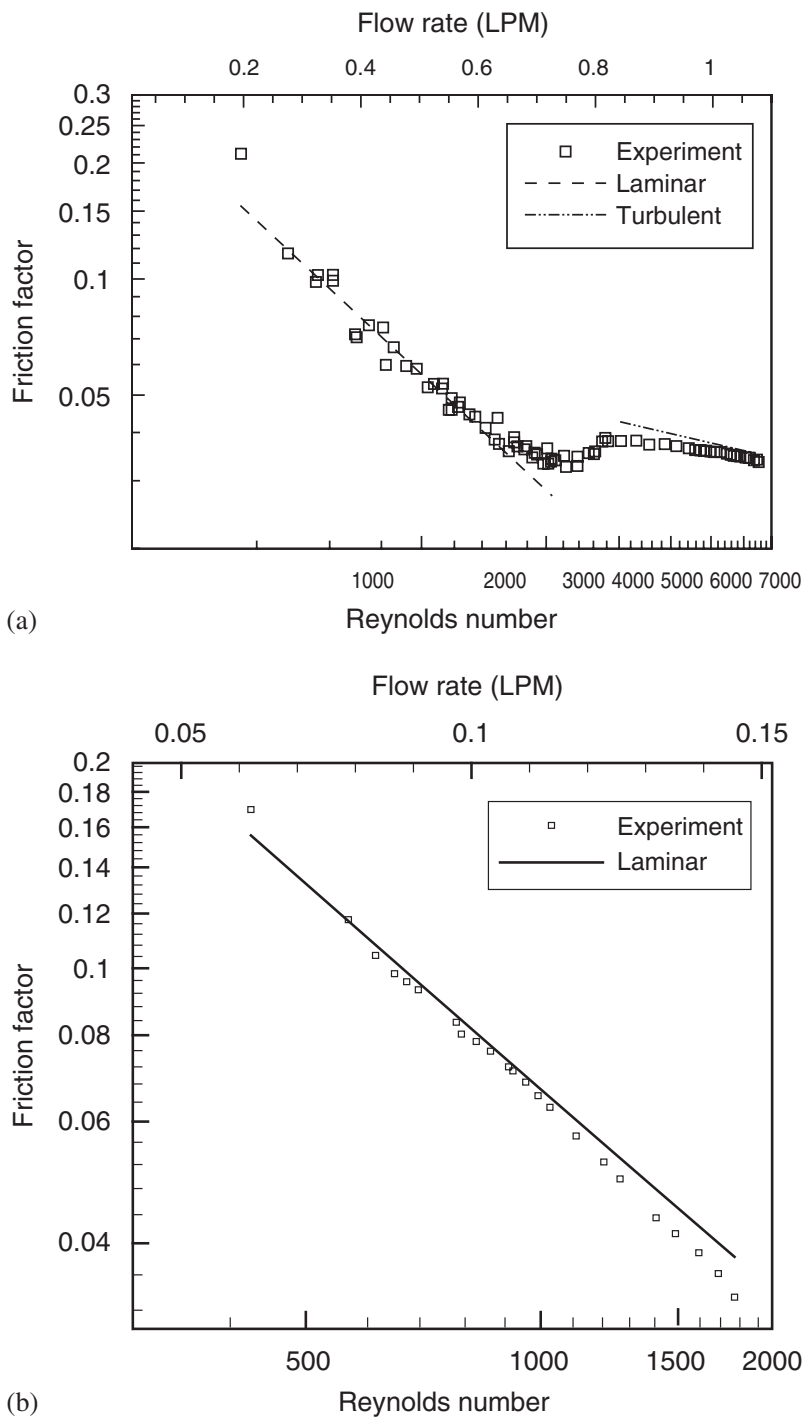

Fig. 3. Variation of friction factor with Reynolds number: comparison of experiment and theory for (a) long channel of $D_{\mathrm{h}}=974 \mu \mathrm{m}$, and (b) short channel of $D_{\mathrm{h}}=244 \mu \mathrm{m}[12]$.

mally developing laminar flow, fully developed laminar flow and turbulent flow. A Navier-Stokes based computational fluid dynamics (CFD) analysis was also conducted to compare with the experimental measurements. The results show that conventional correlations usually underpredict the heat transfer in the laminar regime due to mismatch of boundary conditions and lack of incorporation of aspect ratio effects. However, the experimental data agree with the thermally developing predictions of CFD analysis at low Reynolds numbers, approaching the simultaneously developing values at higher Reynolds numbers in the laminar range. This suggests that a continuum modeling approach can be employed with confidence for predicting heat transfer behavior in microchannels in the dimensional range considered here. In the transitional and turbulent regimes, improved correlations are needed to account for the developing conditions. 

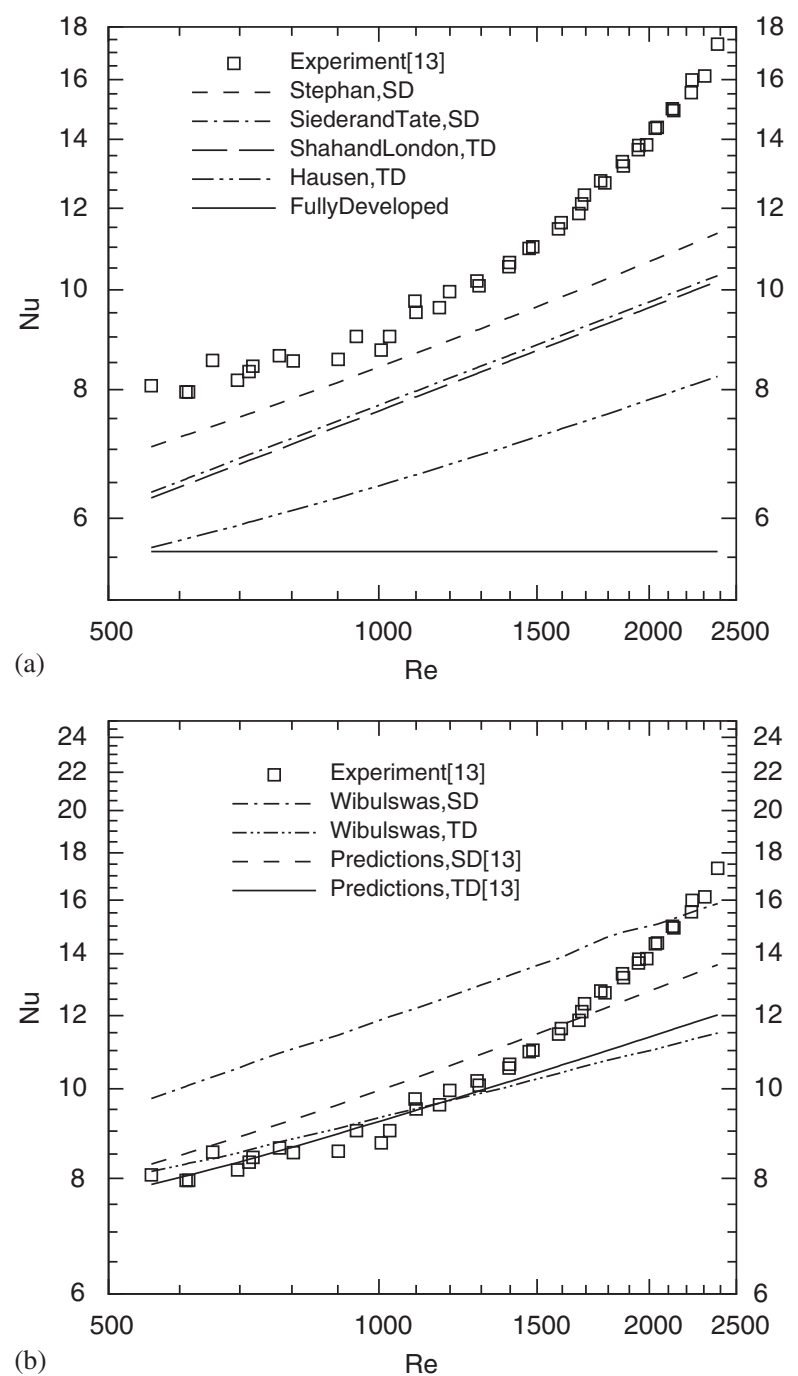

(b)

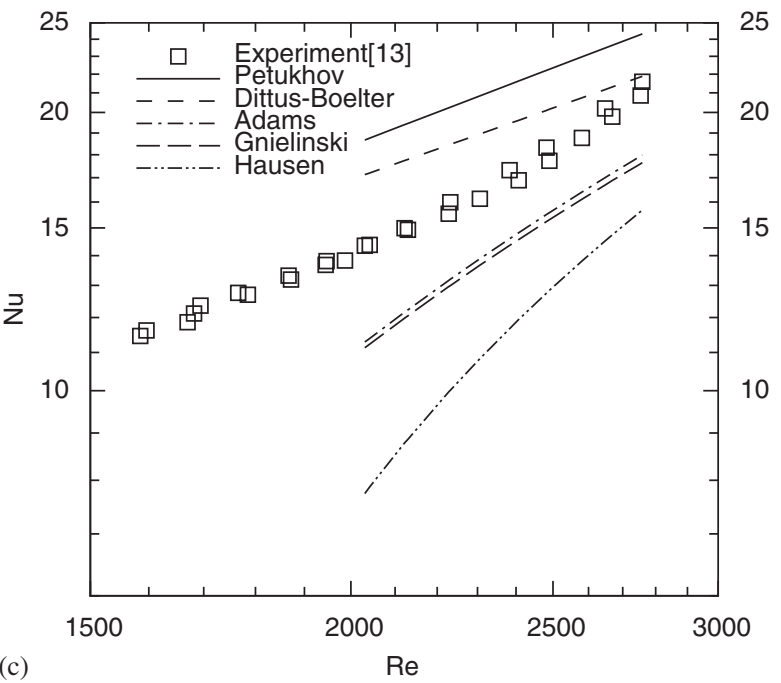

Fig. 4. Variation of Nusselt number with Reynolds number: comparison of experimental data for microchannels of $D_{\mathrm{h}}=318 \mu \mathrm{m}$ with (a) laminar correlations, (b) laminar numerical predictions, and (c) turbulent predictions. The Reynolds number in the plots is a nominal value in that it is calculated based on water properties at the inlet temperature; SD and TD in the legends indicate Simultaneously Developing and Thermally Developing.

\subsection{Assessment of pumping requirements}

The large pumping power requirement of microchannel heat sinks is one of the reasons for their not being widely used on a commercial scale to date. A graphical method to assess the suitability of candidate pumps for a particular microchannel heat sink application was reported in [14].

Two thermal limits are used to calculate the operating regions of microchannel heat sinks for given values of heat removal rate and channel dimensions:

(1) The maximum temperature gradient on the chip is limited to $(\mathrm{d} T / \mathrm{d} x)_{\max }$, i.e., $(\mathrm{d} T / \mathrm{d} x)_{\mathrm{d}}<(\mathrm{d} T / \mathrm{d} x)_{\max }$.

(2) The maximum temperature at any point on the chip should be less than $T_{\max }$, i.e., $T_{\mathrm{d}}<T_{\max }$.

The minimum volume flow rate and the minimum pressure drop set by the first condition are represented by Eqs. (1) and (2) below, while those set by the second limit are given by Eqs. (3) and (4)

$$
\begin{aligned}
& \left.Q>\frac{q}{\rho c_{\mathrm{p}} L_{\mathrm{d}}(\mathrm{d} T / \mathrm{d} x)_{\max }}\right) \frac{(1+\alpha)^{2}}{\alpha^{3}} g_{2}(\alpha) \frac{w_{\mathrm{c}}+w_{\mathrm{w}}}{w_{\mathrm{c}}^{4}} \\
& \Delta p>\left(\frac{q \mu}{8 \rho c_{\mathrm{p}} W_{\mathrm{d}}(\mathrm{d} T / \mathrm{d} x)_{\max }}\right. \\
& Q>\left(\frac{q}{\rho c_{\mathrm{p}}}\right) \frac{1}{\left(T_{\max }-T_{f, i}-\frac{q\left(w_{\mathrm{c}}+w_{\mathrm{w}}\right)}{g_{1}(\alpha) k L_{\mathrm{d}} W_{\mathrm{d}}} \frac{\alpha}{(1+\alpha)^{2}}\right)} \\
& \Delta p>\left(\frac{q \mu L_{\mathrm{d}}}{8 \rho c_{\mathrm{p}} W_{\mathrm{d}}}\right) \frac{\frac{(1+\alpha)^{2}}{\alpha^{3}} g_{2}(\alpha) \frac{w_{\mathrm{c}}+w_{\mathrm{w}}}{w_{\mathrm{c}}^{4}}}{\left(T_{\max }-T_{f, i}-\frac{q\left(w_{\mathrm{c}}+w_{\mathrm{w}}\right)}{g_{1}(\alpha) k L_{\mathrm{d}} W_{\mathrm{d}}} \frac{\alpha}{(1+\alpha)^{2}}\right)}
\end{aligned}
$$

The results are illustrated in Figs. 5(a) and (b) in terms of limiting pressure drop $(\Delta p)$ and total volume flow rate $(Q)$. If the flow rate and pressure drop at which the microchannel heat sink operates lie within the operating region, the desired heat transfer rate will be achieved and the two thermal limits will be met, as defined by the 'operating region' in Fig. 5(a).

The suitability of a pump to a microchannel heat sink design is assessed by superimposing the pump curve and the required minimum operating limit for the heat sink, as in Fig. 5(b). The point of intersection would be the operating point of the pump and heat sink. This approach provides a very simple way of assessing the suitability of any pump and microchannel heat sink for a desired application.

The point of intersection of the two limiting curves also represents the minimum pumping requirements of the microchannel heat sink. The microchannel width corresponding to this point would be optimal for a prescribed aspect ratio, and the heat sink with these dimensions would impose the minimum requirements on the pump to drive the fluid through the microchannels. 


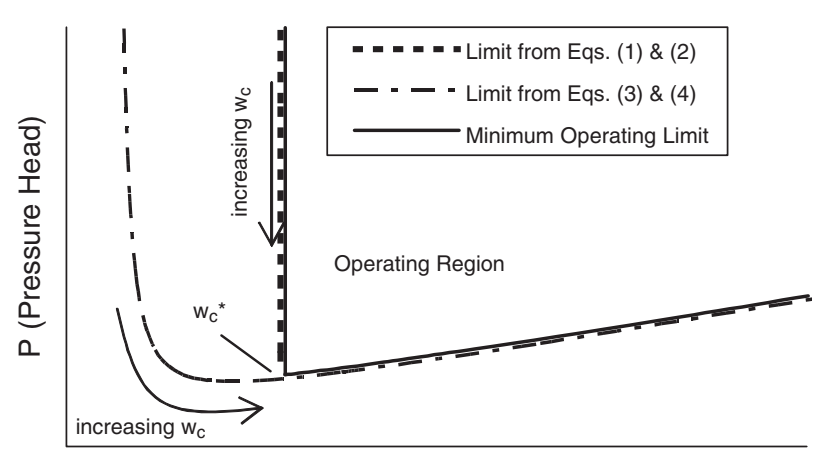

(a)

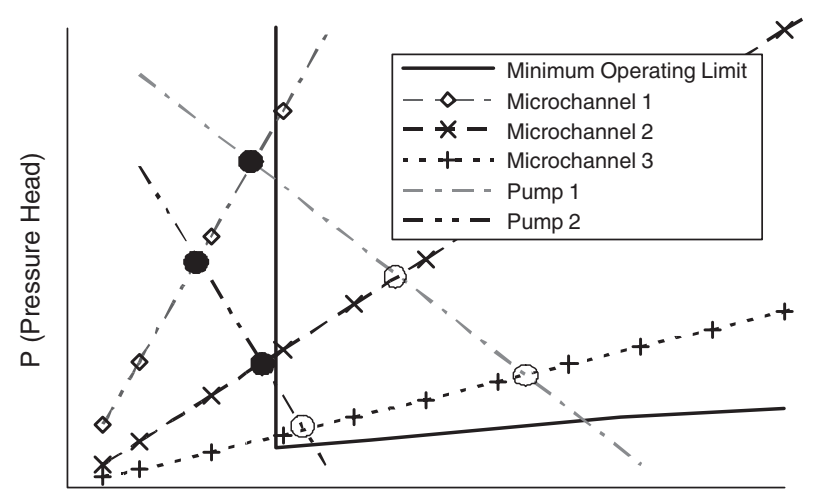

(b)

$\mathrm{Q}$ (Flowrate)

Fig. 5. (a) Pumping requirements of microchannel heat sinks of fixed aspect ratio, and (b) graphical assessment of the suitability of pumps to microchannel heat sinks of fixed aspect ratio [14]. Details of the pumps and microchannels considered are also available in the original reference.

\subsection{Review of micropumping techniques}

A primary consideration in the implementation of microchannel heat sinks is to understand and evaluate the methods for actuating flow at the microscale. Integrating the pumping action directly at the scale of the microchannels in a heat sink is an attractive alternative to the use of external pumps. A comprehensive review of micropumping techniques was generated by Singhal et al. [15], with an emphasis on small-scale cooling applications. Micropumps are compared based on their working principles, limitations and advantages, the maximum achievable flow rate per unit cross-sectional area of the pump and the maximum achievable back pressure. The micropumps are also compared based on miniaturization potential, size, actuation voltage and power required per unit flow rate, ease and cost of fabrication, minimum and maximum frequency of operation, and suitability to electronics cooling.

Fig. 6(a) shows that the pumps with the highest flow rate per unit area are the injection-type EHD, electroosmotic, flexural plate wave, piezoelectric, rotary and valveless micropumps. From Fig. 6(b), it is seen that piezoelectric, electroosmotic and valveless micropumps yield the highest back pressures. More details of the comparison of micropumps discussed in the literature are available in [15].

\section{Integrated air and liquid micropumps}

Integrated microchannel cooling systems, with micropumps integrated into microchannels, are very attractive because they obviate separate micropumps and can greatly reduce package volume. Equally importantly, their fabrication can be integrated with that of the microchannels thus decreasing the overall cost of the cooling system. Two integrated micropumping approaches, one for air and the other for liquids, are described below.

Schlitz et al. [16] presented a novel method of pumping air at microscale dimensions using the concept of ion drag, called microscale ion-driven air flow (MIDAF). The concept is schematically illustrated in Fig. 7. Ions are generated in air using low-voltage cold-cathode electron emitters that inject electrons into the air. Once in the air, the electrons generate ions by collision reactions. This is similar to the corona wind concept described by Robinson [17], except that it is accomplished at lower voltages. The ions are moved by a series of microfabricated electrodes that generate strong electric fields to pump ions through air. Ahn and Kim [18] used a similar approach to generate a traveling electric field to pump alcohol. Ions collide repeatedly with neutral molecules, thus generating bulk motion of the gas. Meso-scale motion, flow on the order of millimeters, is obtained using a traveling electric field which is established by an array of electrodes (Fig. 8).

Analytical and numerical models of the fluid-ion-electric field interactions have been developed. First-order analyses demonstrate the feasibility of implementing this concept into a heat sink with cooling rates as high as $40 \mathrm{~W} / \mathrm{cm}^{2}$. Numerical modeling results in [16] describe the body force interaction of the ions with the fluid, the location of the body force, the resulting velocity profiles, the stability of ion clouds and the important parameters that affect this flow. The MIDAF concept has been experimentally verified by means of ion current measurements. Measurable ion currents were established over a flat test section with pumping electrodes spaced apart by $30 \mu \mathrm{m}$, operating at potentials of $0-35 \mathrm{~V}$, and switching at a frequency of 1.4 MHz.

A liquid micropump design capable of integration into microchannels is shown in Fig. 9 [19,20]. This design combines induction electrohydrodynamics (EHD) with a valveless nozzle-diffuser micropump actuated using a vibrating diaphragm. Several of these micropumps can be arranged in series and parallel, as shown in Fig. 9(c), to achieve both high flow rates and high pressure drops. The micropump is based on integration of two existing technologies: a valveless nozzle-diffuser micropump [21] and induction EHD [22,23].

A comprehensive numerical model of the micropump has been developed to study the combined effect of the valveless micropump with vibrating diaphragm and EHD. The numerical model has been validated in detail using theoretical and experimental results from the literature. 

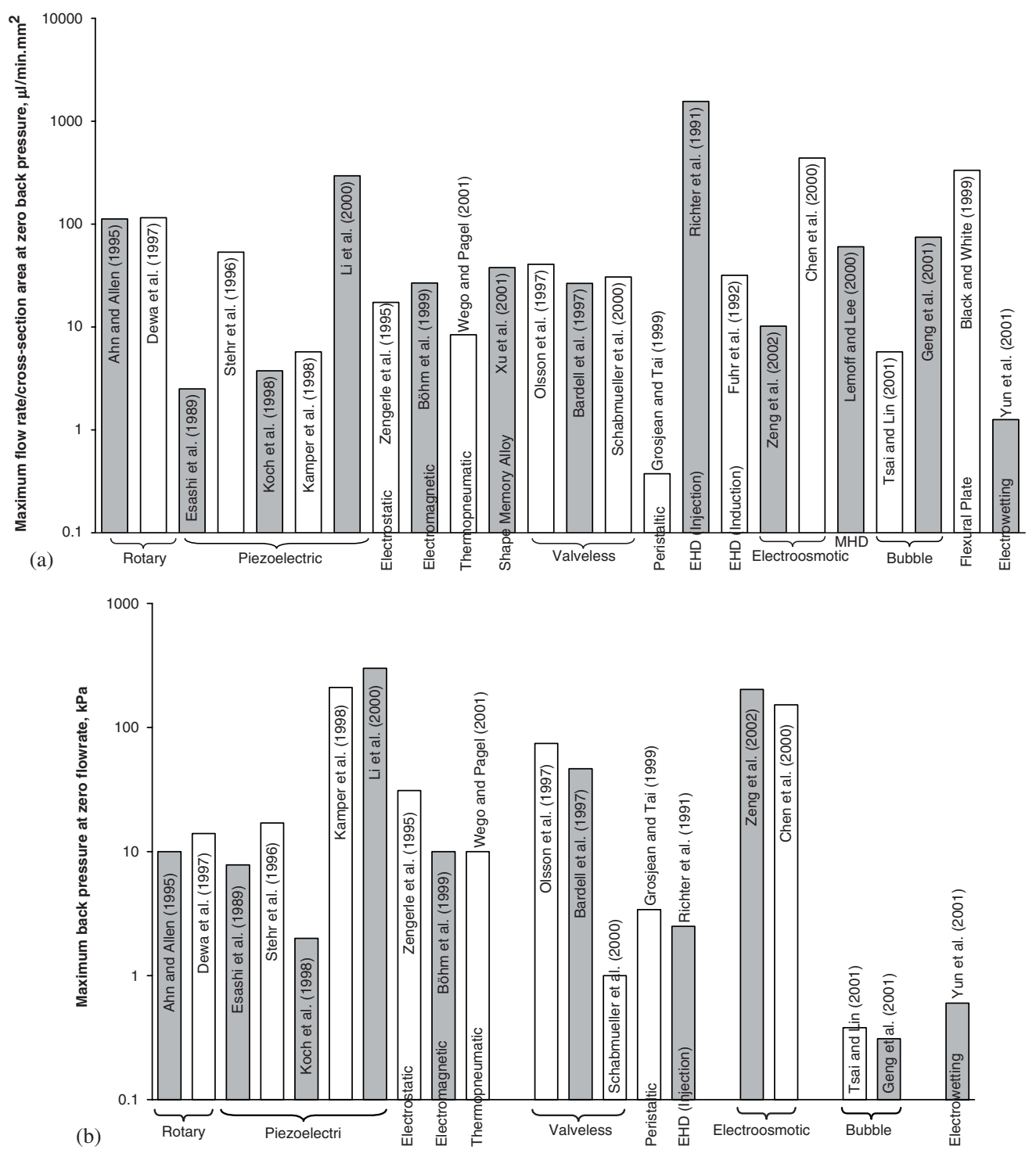

Fig. 6. (a) Maximum flow rate per unit cross-sectional area at zero back pressure, and (b) maximum back pressure at zero flow rate, of various micropumps presented in the literature [15].

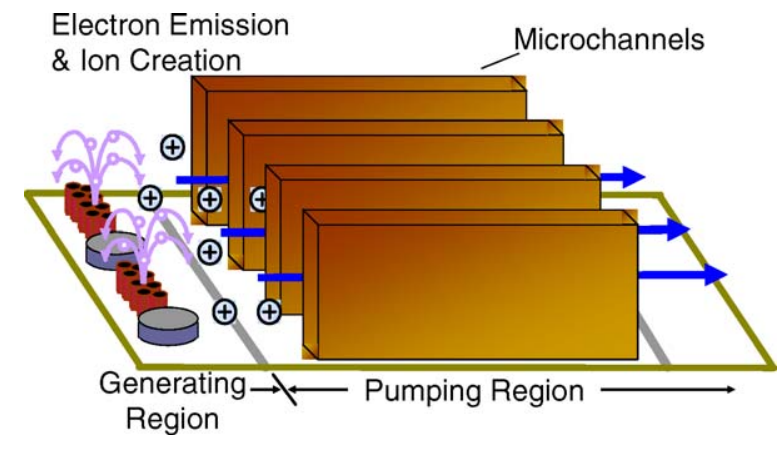

Fig. 7. Illustration of microscale ion driven air flow.

EHD leads to significant improvement in flow rate over that of the vibrating diaphragm alone. Velocity vectors in the mid-plane in a valveless micropump with and without the EHD action are shown in Fig. 10. The velocities with

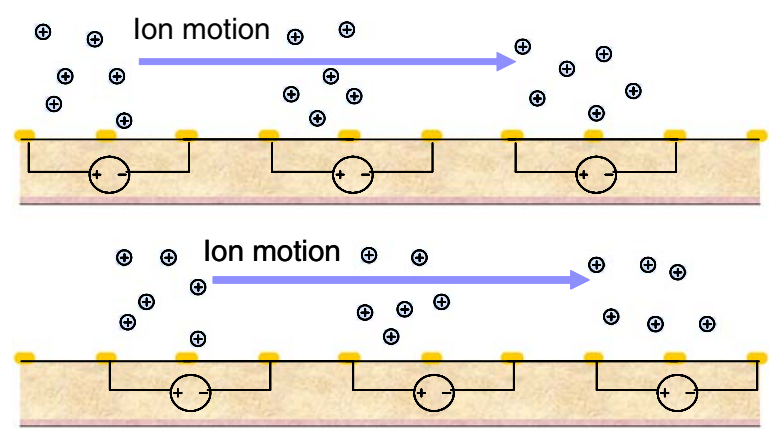

Fig. 8. Meso-scale motion obtained by use of a translating electric field.

EHD action are much higher than those in the absence of EHD. Singhal et al. [24] studied the flow characteristics of nozzle-diffuser elements at low Reynolds numbers, typical of those found in such micropumps. 

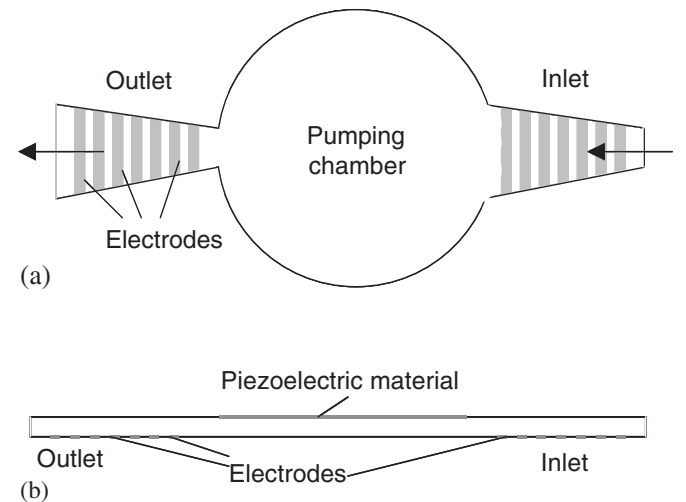

(b)

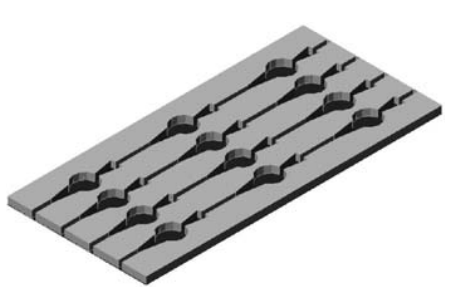

(c)

Fig. 9. (a) Top view, and (b) side view of new micropump design; (c) integration of micropumps in a microchannel heat sink [19].

\subsection{Infra-red micro-particle image velocimetry (IR-PIV)}

A non-intrusive diagnostic technique, infrared microparticle image velocimetry (IR-PIV), was developed by Liu et al. [25] for measuring flow fields within MEMS devices with micron-scale resolution. This technique capitalizes on the transparency of silicon in the infrared region, and overcomes the limitation posed by a lack of optical access with visible light to sub-surface flow in silicon-based microstructures. Experiments with laminar flow of water in a circular micro-capillary tube of diameter $255 \mu \mathrm{m}$ were conducted to demonstrate the efficacy of this technique. Sample experimental measurements are illustrated in Fig. 11, indicating very good agreement with velocity profiles predicted from laminar theory. The results indicate that the IR-PIV technique effectively extends the application of regular micro-PIV techniques, and has great potential for flow measurements in silicon-based microdevices.

\section{Jet impingement}

The enhanced heat transfer rates obtained with impinging jets make them very suitable for cooling electronic devices with very high heat dissipation rates. The topic has received wide attention and several theoretical and experimental studies have been performed in the literature. A detailed review of confined jets is available in [26]. In confined jets, the outflow is confined to a parallel-plates arrangement by the presence of a horizontal confining wall extending around the orifice, above the impingement surface (as illustrated in the visualization shown in Fig. 12). Confined jets are also submerged, i.e., the ambient fluid is the same as the impinging jet. This is in contrast to free-
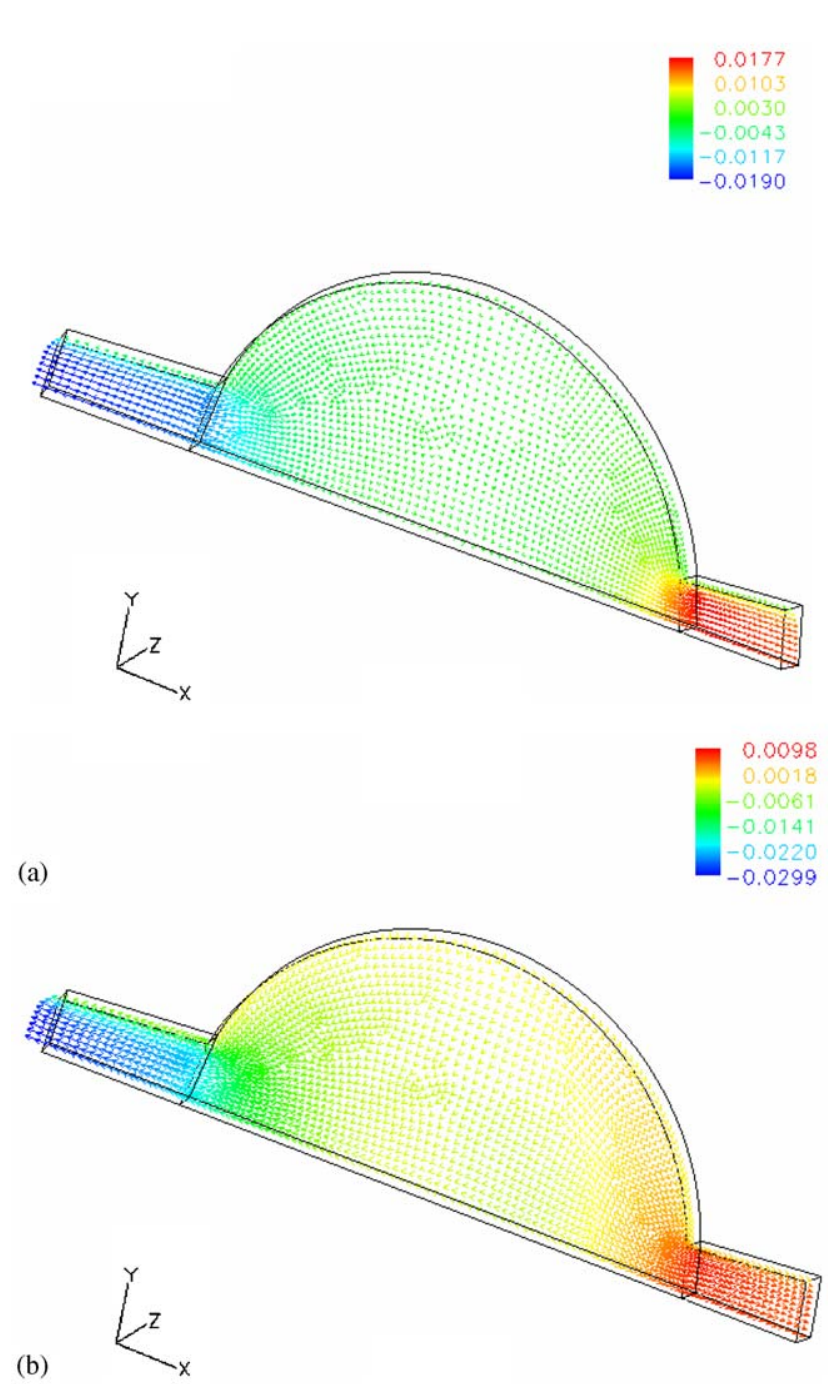

Fig. 10. Velocity vectors in a valveless micropump (a) with and (b) without EHD action.

surface jets where the fluid issuing from the jet is different from the ambient fluid, resulting in a distinct free surface separating the two fluids.

Much of the literature on impinging jets has focused on flow and geometric parameters such as jet flow rate, fluid properties, jet-to-target spacing and jet diameter; in a majority of the studies, the jets considered have been implemented as free-surface or submerged jets which are not confined. Confinement of the jet outflow is relevant in many practical applications, especially in electronics cooling.

Relative to free-surface jets, submerged jet impingement results in higher heat transfer rates [27], and conversely, confinement of the outflow causes a reduction in heat transfer [28], in general terms.

\subsection{Single jets}

For single round jets, the local heat transfer coefficient on the target surface has a bell-shaped distribution with 

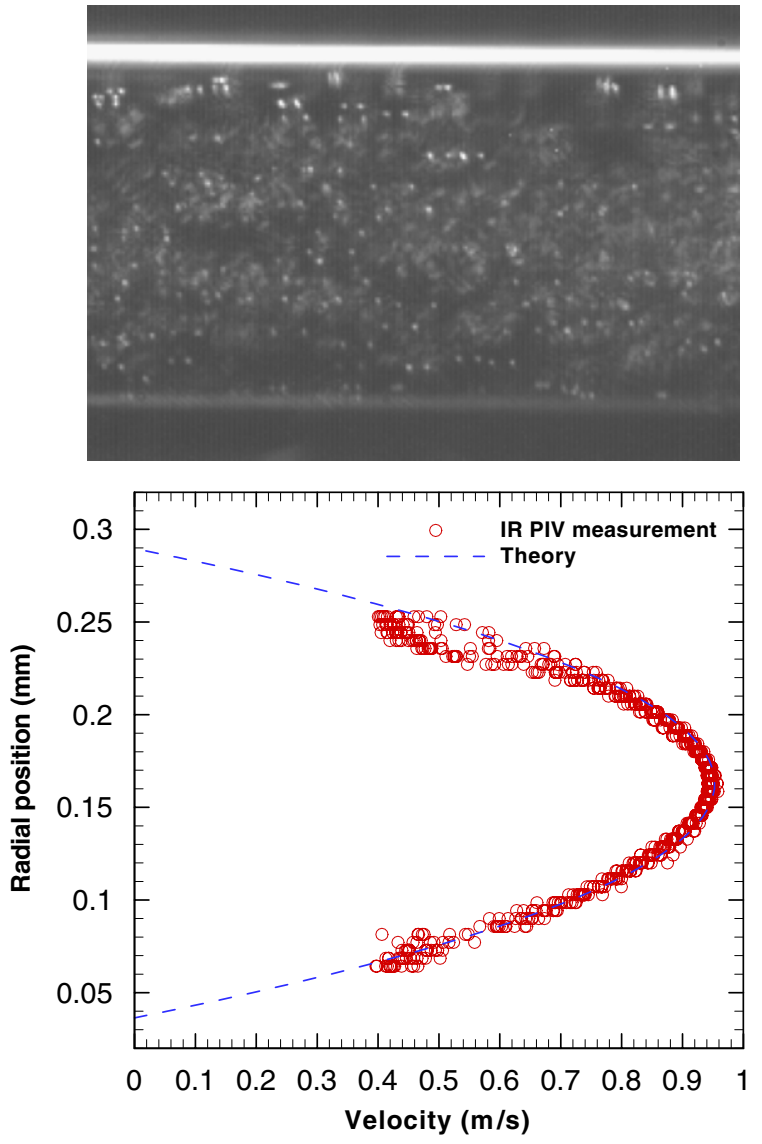

Fig. 11. IR-PIV image (above) and processed results (below) for $u_{m}=$ $0.50 \mathrm{~m} / \mathrm{s}(\operatorname{Re}=126)$.

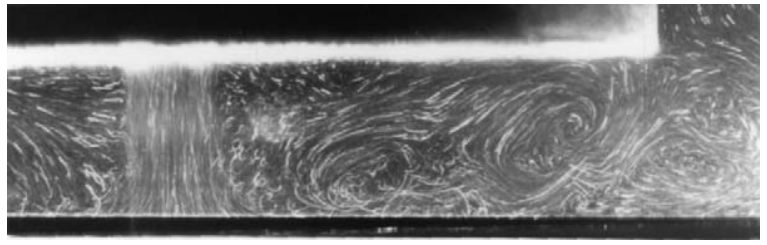

Fig. 12. Flow field visualized in a confined and submerged liquid jet of fluorinert FC-77 [26] (with nozzle diameter of $12.7 \mathrm{~mm}$, Reynolds number of 2000, and orifice-to-target spacing of two jet diameters).

respect to radial distance from the stagnation point. The maximum value occurs at the stagnation point and decreases symmetrically with radial distance. The radial distribution of the heat transfer coefficient as a function of orifice to target spacing $(d=1.59 \mathrm{~mm}, R e=13000)$ in confined and submerged liquid jet impingement is shown in Fig. 13 [29], and suggests a potential core that is 4 diameters long. The figure also shows the presence of secondary peaks located at $r / d \approx 2$ in the curves for small orifice-to-heat source spacings $(H / d<5)$. For $H / d \geqq 5$, the peaks manifest as inflection points, and, with increasing $H / d$, as mere changes in slope.

Area-averaged (over the area of the heat source) Nusselt numbers for liquid jets of four different diameters are compared in Fig. 14 [29]. Each orifice shows the expected increase in average Nusselt number with increasing

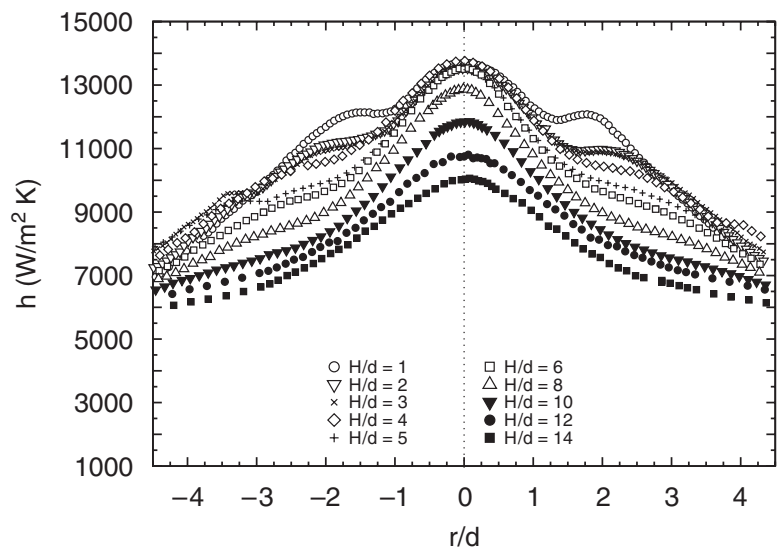

Fig. 13. Variation in local heat transfer coefficient distribution with jet to target spacing $(H / d)$ for $R e=13000$ (based on orifice diameter, $d$ ) and $d=1.59 \mathrm{~mm}[29]$.

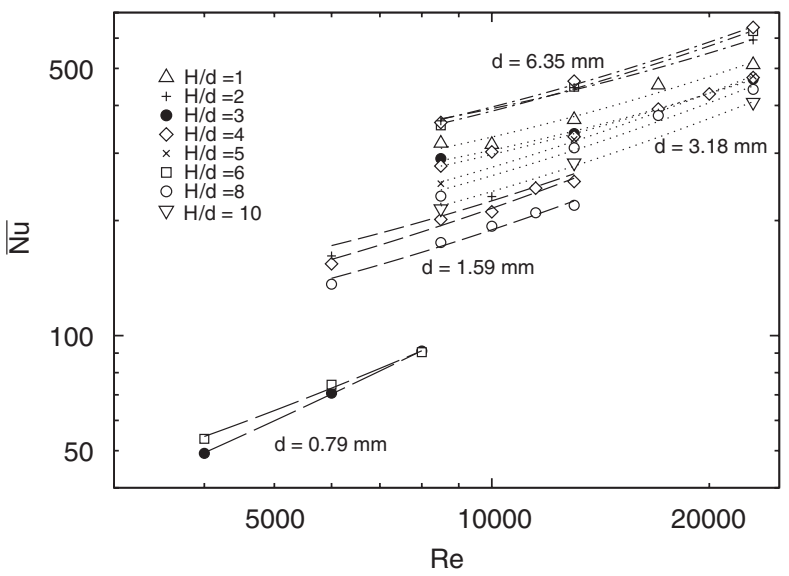

Fig. 14. Variation of area-averaged Nusselt number with Reynolds number for four liquid jets at different jet-to-target spacings [29].

Reynolds number. The data from each orifice fall into a distinct group separated by orifice diameter. There is a slight increase in the dependency on Reynolds number as the diameter is increased. Results for a similar study with air jet impingement are available in [30].

Garimella and Nenaydykh [31] and Schroeder and Garimella [30] proposed generalized correlations which represent the data on confined impingement of liquid and air jets, respectively. They demonstrated the need for additional information concerning the effects of fluid thermophysical properties, turbulence levels, orifice geometry, and heater-to-orifice size. Correlations for areaaveraged heat transfer coefficients in confined jet impingement have been reported for air [30] and liquid [29] jets. Li and Garimella [32] proposed the most general correlations for confined and submerged jet impingement, valid for a wide range of fluids including air, water and fluorinert liquids, as well as a large range of geometric parameters.

\subsection{Multiple jets}

Use of multiple confined jets leads to crossflow streams where accumulated drainage due to spent fluid from each 


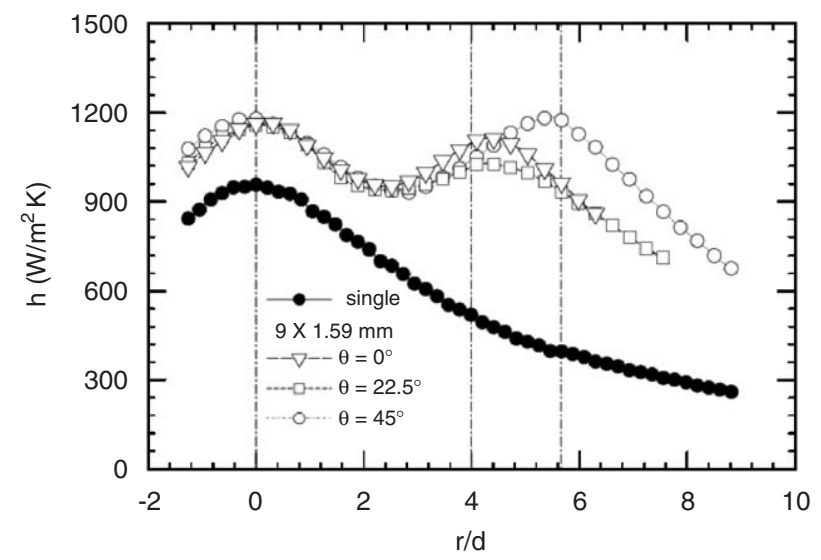

Fig. 15. Local heat transfer coefficient distributions for the $9 \times 1.59 \mathrm{~mm}$ array (open symbols) at $R e=15000$ and $H / d=4$. The dashed vertical lines indicate the centers of the array jets located at $r / d=0,4$, and $42(S /$ $d=4)$. Single-jet results at the same $R e$ and $H / d$ are plotted for comparison (solid symbols) [35].

jet adds a crossflow component to the existing impinging flow field. The flow field for these multiple jet configurations is complicated by interference between neighboring jets prior to impingement, as well as by collision of the developing wallflows from adjacent orifices [33]. Huber and Viskanta [34] studied the interactions between neighboring jets for confined and submerged air jets. An orifice-to-target spacing $(H / d)$ of 0.25 was shown to result in minimal pre-impingement interaction, thus leading to much improved heat transfer relative to a larger $H / d$ of 6 . The secondary maxima were also much more pronounced at the smaller spacings.

The local heat transfer to an array of impinging jets is a complex function of Reynolds number, orifice-target spacing, number of jets, interjet spacing, and outflow (exhaust) configuration. Garimella and Schroeder [35] obtained the local heat transfer distribution for a $9 \times 1.59 \mathrm{~mm}$ array of confined air jets, as illustrated in Fig. $15(R e=15000, H / d=4)$. The jet-array data are plotted against distance from the centerline $(r / d)$, and terminate when the end of the heated surface is reached. The corresponding single jet heat transfer coefficient distribution for the same $R e$ and $H / d$ is also plotted in the figure for comparison.

The effect of orifice-to-target spacing on the local heat transfer coefficients for the same array is illustrated in Fig. 16 for $R e=5000$ and 15,000 . It is evident that a decrease in the orifice-target spacing from $H / d$ of 4-1 results in an increase in heat transfer coefficients for both Reynolds numbers. The effect is stronger at the higher Reynolds number: for a decrease in $H / d$ from 4 to 1 , the percentage increase in average heat transfer coefficient at $R e=15000$ is twice (from 883 to $1142 \mathrm{~W} / \mathrm{m}^{2} \mathrm{~K}$ ) the increase at $R e=5000$ (from 446 to $509 \mathrm{~W} / \mathrm{m}^{2} \mathrm{~K}$ ).

The influence of Reynolds number on the local heat transfer coefficients is shown in Fig. 17 for the same array for $R e=15,000$ and 5000 at two different spacings of $H / d=4$ and 1 . Corresponding single-jet results at the same

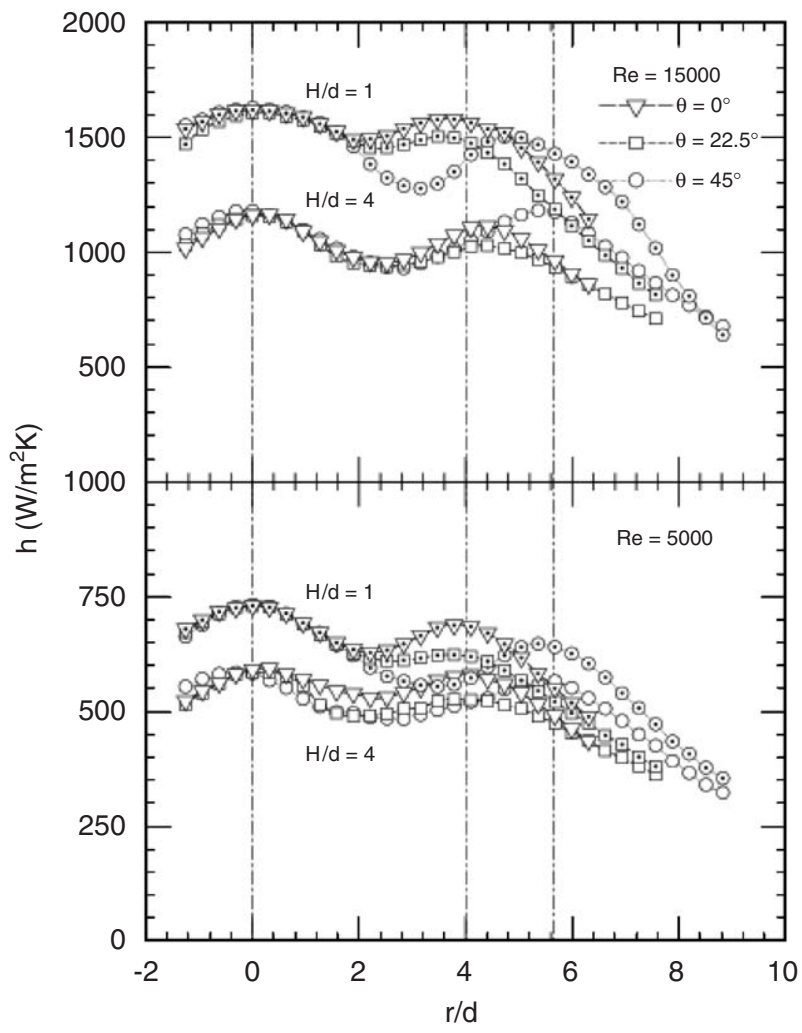

Fig. 16. Variation in the $9 \times 1.59 \mathrm{~mm}$ array heat transfer coefficients with orifice-target spacing for $R e=15000$ (top) and 5000 (bottom) [35].

$R e$ and $H / d$ are also included for comparison. As the Reynolds number is increased at a fixed $H / d$, the local heat transfer coefficients also increase, as expected. The $H / d=4$ spacing is characterized by distinct peaks in heat transfer coefficient at the locations of the centers of the jets $\left(r / d=0 ; \quad r / d=4: \quad \theta=0 ; \quad\right.$ and $\left.r / d=42: \quad \theta=45^{\circ}\right)$. The distribution is flatter for the smaller spacing of $H / d=1$. The array heat transfer also increases faster with increasing Reynolds number than in the case of the single jet at the smaller $H / d$. The increase in average heat transfer coefficient as Reynolds number increases from 5000 to 15,000 with $H / d=1$ is $124 \%$ for the array but only $87 \%$ for the single jet. At $H / d=4$, the increase in average heat transfer coefficient with Reynolds number is roughly the same $(\sim 100 \%)$ for both the array and the single jet. It is also apparent that the stagnation-region heat transfer coefficient for the central jet in the array exceeds the corresponding (i.e., at the same $R e$ and $H / d$ ) single-jet value in all cases in Fig. 17.

Variation in the local and average heat transfer coefficients for a different jet array $(4 \times 3.18 \mathrm{~mm})$ was also studied. Correlations for area-averaged Nusselt number for arrays of multiple jets are also presented in [35].

\subsection{Geometry effects}

Garimella and Schroeder [35] and Fitzgerald and Garimella [36] studied the effect on heat transfer of the 


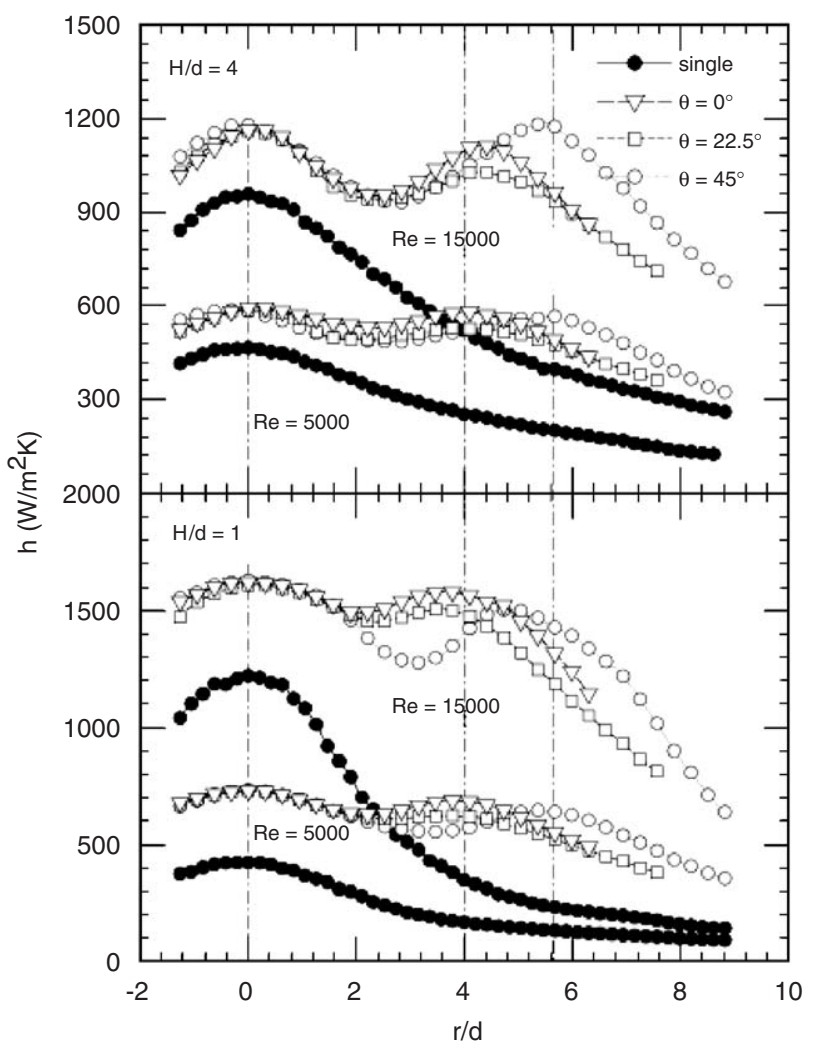

Fig. 17. Effect of Reynolds number on the $9 \times 1.59 \mathrm{~mm}$ array heat transfer coefficients for $H / d=4$ (top) and 1 (bottom). Single-jet results at the same $R e$ and $H / d$ are plotted for comparison (solid symbols) [35].

flow field caused by different orifice lengths (or the lengthto-diameter aspect ratio) and orifice diameters. Other studies on this topic are reviewed in [26]. Orifice geometry affects the turbulence levels generated in the orifice as well as the shape of the exit velocity profile, both of which affect the local heat transfer coefficients.

Garimella and Nenaydykh [31] studied the effect of the orifice length-to-diameter $(l / d)$ aspect ratio on the heat transfer distributions at a range of orifice-to-target spacings. Their results revealed that the aspect ratio plays a more dominant role in determining heat transfer coefficients at the smaller spacings $(H / d \leq 4)$. In contrast to $H / d$, the role of aspect ratio on heat transfer was unaffected by Reynolds number. In all cases, very short orifices $(l / d<1)$, both stagnation and average heat transfer coefficients were significantly higher than for $l / d \geqq 1$; in this latter range, the influence of aspect ratio was less pronounced.

The orifice diameter is also an important and independent parameter affecting heat transfer in jet impingement. Garimella and Nenaydykh [31] illustrated a dependence on diameter for local Nusselt number distributions, even with geometrically similar orifices. The influence of orifice diameter was most pronounced in the stagnation region. The velocimetry measurements of Fitzgerald and Garimella [37] revealed higher levels of turbulence as the orifice diameter was increased, with all other parameters held constant.

Another important geometry parameter in confined jet impingement is the heater-to-orifice size ratio $\left(D_{\mathrm{e}} / d\right)$. San et al. [38] assessed the effect of varying $D_{\mathrm{e}} / d$ on the heat transfer distribution. Increasing the heater size served to degrade the entire heat transfer distribution and reduce the magnitude of the secondary peaks. The heater size had a more significant effect on the formation and shape of the secondary peaks than did variations in the orifice diameter. The effect of increasing the heater diameter was significant: a roughly threefold increase in the heater size caused a $50 \%$ decrease in the stagnation heat transfer coefficient. Schroeder and Garimella [30] also found that this size ratio had a significant effect on the stagnation and average heat transfer coefficients in confined jet impingement.

\subsection{Numerical modeling}

Several studies have been performed on the modeling of impinging jets, as reviewed by Polat [39]. More recent literature in this field has been reviewed by Garimella [26]. Numerical modeling of the flow field of a confined and submerged impinging liquid jet by Morris and Garimella [40] predicted the location of the center of the toroidal recirculation pattern in the confinement region at several orifice-to-target plate spacings. While the primary features of the recirculating flow patterns were realized, the standard high-Reynolds number $k-\varepsilon$ model used failed to predict the secondary flow patterns observed visually in the confined outflow. More recently, Morris et al. [41] improved these predictions by using the Reynolds stress turbulence closure model, with which the secondary flow patterns were also satisfactorily captured.

Morris et al. [42] applied a two-layer model for predicting heat transfer in confined jet impingement to better account for the local variations of turbulence quantities near the wall. The turbulent Prandtl number concept was used to evaluate the eddy diffusivity for heat in the $k-\varepsilon$ model. Four turbulent Prandtl number functions were investigated and evaluated for agreement of predictions with experiments in the literature.

\subsection{Surface enhancements}

The heat transfer rates obtained in confined jet impingement may be significantly enhanced by target surface modification, that is, by employing surface roughness, extended surfaces or heat sinks on the target surface $[26,43,44]$. In liquid jet impingement with finned surfaces, reductions in thermal resistances of approximately $50 \%$ have been reported; with further roughening of the spreader plate, the thermal resistance was reduced by as much as $80 \%$ [45]. In addition to the actual surface enhancements employed, parameters such as the orifice diameter, flow rate, orifice-to-target spacing and number of orifices also affect the heat transfer rates obtained with 
enhanced surfaces. Brignoni and Garimella [46] conducted a study to optimize the confined impingement configuration for a given pin-fin heat sink. A highly effective copper pin-fin heat sink was considered for the optimization of jet impingement. El-Sheikh and Garimella [47,48] studied much larger heat sinks with single and multiple confined air jets and obtained enhancement factors of up to 72 compared to the unenhanced surface.

\section{Heat pipes}

Heat pipes are widely used in electronics cooling applications, both as efficient heat spreaders and to transport heat to remote heat sinks for dissipation. The analysis of the operation and performance of heat pipes has received a lot of attention, and a comprehensive review is available in Garimella and Sobhan [49]. For the most part, attention has been focused on the study of either flat or round heat pipes, typically with single heat sources. There has been recent interest in exploring the use of flat heat pipes as substrates upon which multiple heat generating components are mounted. In such a configuration, the heat pipe acts both as a heat spreader as well as a conveyer of heat, while also providing the mechanical substructure. The performance of flat heat pipes under these types of heterogeneous and distributed loads is not well understood, and has been a focus of study in the author's group.

Vadakkan et al. [50] developed a complete two-dimensional mathematical model to analyze the transient and steady-state performance of flat heat pipes. The model accounts for the pressurization of the vapor core and the coupling of the continuity, momentum and energy equations in the wick and vapor regions. A stable numerical procedure was devised to solve the resulting governing equations. The procedure improves upon the standard sequential solution scheme by recognizing the sensitivity of the mass flow rate at the phase change interface to the interface temperature and pressure, as well as the system pressure. The improved method was shown to perform well over a range of heat inputs, and predictions showed satisfactory agreement with experiments.

This model was used by Vadakkan et al. [51] to study the performance of flat heat pipes with multiple discrete heat sources (as illustrated in Fig. 18). The effect of heat source strength and separation and their effect on steady as well as transient performance were studied. The simulations were

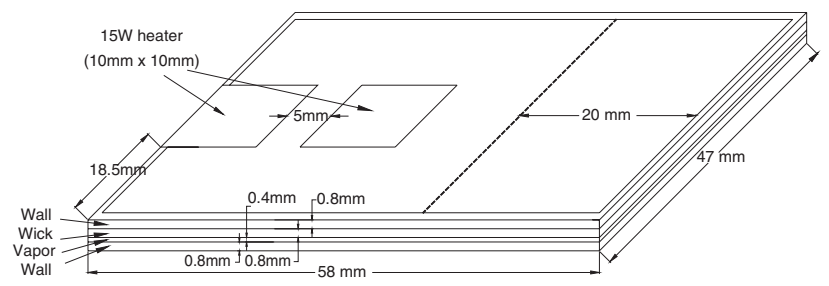

Fig. 18. Schematic diagram of the flat heat pipe investigated; the thickness dimension has been greatly exaggerated in this schematic to delineate the different parts of the heat pipe [51]. used to assess the possibility of dryout as well as the location at which dryout might first be observed. The maximum pore radius necessary to support the pressure drop at the evaporator interface could also be obtained from the hydrodynamic pressure variation at the interface.

The three-dimensional analysis includes the liquid wick and the wall in addition to the vapor core. An equilibrium model for heat transfer and a Brinkman-Forchheimer extended Darcy model for fluid flow in the wick region are employed. The density change in the vapor due to pressurization is calculated using the ideal gas state equation. The mass flow rate, temperature and pressure at the interface are determined using an energy balance at the interface in conjunction with kinetic theory and the Clausius-Clapeyron equation. The energy balance at the interface includes convection and conduction on the liquid and vapor sides. Vapor flow, temperature and hydrodynamic pressure fields are computed from coupled continuity/momentum and energy equations in the vapor and wick regions, and a conduction analysis in the wall. The flow of the vapor is assumed as laminar and incompressible. At high heat fluxes, the vapor velocity may be high enough for compressibility effects to become important; these are not accounted for in the present development, but are being included in the formulation in ongoing work.

The physical dimensions of the flat heat pipe considered are shown in Fig. 18. The heat pipe dimensions, $47 \mathrm{~mm}$ width and $58 \mathrm{~mm}$ length with a wall thickness of $0.8 \mathrm{~mm}$ on all six sides, simulate those of typical commercially available flat heat pipes. The condenser covers $20 \mathrm{~mm}$ of the heat pipe as shown in the figure. The wall and wick are made of copper and the working fluid is water. The wick is present only on one side of the heat pipe, and the heating and cooling boundary conditions are applied only on this wicked side. Two discrete $10 \times 10 \mathrm{~mm}$ heat sources are mounted at a separation distance of $5 \mathrm{~mm}$ in the baseline case. The heat input to each heat source is $15 \mathrm{~W}$. Those portions of the heat pipe surface not exposed to the condenser or evaporator boundary conditions are assumed adiabatic.

Contours of the wall temperature variation on the wicked side of the heat pipe $(y=2.8 \mathrm{~mm})$ at steady state are shown in Fig. 19(a). The baseline case is considered, with equal heat inputs to the two sources. The maximum temperature occurs at the center of the heat source on the left. Conduction down the side wall is responsible for the maximum temperature not occurring at the left end of this heat source. The temperature decreases with distance away from the heated zone. The temperature distribution along the vertical midsection $(z=23.5 \mathrm{~mm})$ of the heat pipe is shown in Fig. 19(b). The highest temperatures are in the vicinity of the discrete heat sources. In the vapor region, a significant drop of $12{ }^{\circ} \mathrm{C}$ in temperature along the axial direction is observed, indicating continual energy transfer into the vapor across the liquid-vapor interface. In cases where the effect of convection in the vapor may be dominant over diffusion at the liquid-vapor interface, the 

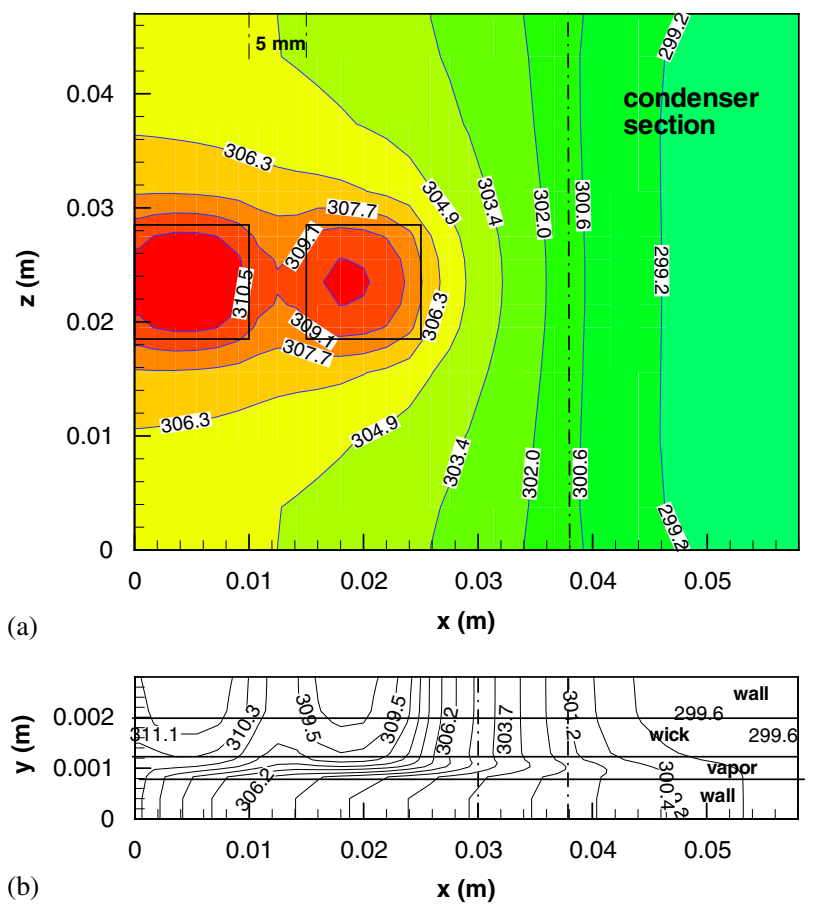

Fig. 19. (a) Temperature contours at the wall $(y / H=1)$ on the wicked side of the heat pipe at an input power of $15-15 \mathrm{~W}$; the condenser section is delineated by the dashed line. (b) Temperature distribution at the mid plane $(z / W=0.5)$ of the heat pipe for the baseline case with $15-15 \mathrm{~W}$ heat input $(d=5 \mathrm{~mm})[51]$.

vapor temperature variation would be significantly smaller. The Peclet number of the vapor space governs which of these processes is dominant. The figure also shows a significant drop in temperature through the wick ( $y$-direction), attributable to the low wick thermal conductivity.

The effect of heat source separation is investigated by holding the power input to the two heat sources constant at 5 and $25 \mathrm{~W}$ for the left and right sources, respectively. The heat source separation is varied through 0,5 and $10 \mathrm{~mm}$ in Fig. 20. As expected, the figure shows that the maximum temperature always occurs at the center of the right heat source with the higher heat input. This maximum temperature reduces from 312.6 to $311.4 \mathrm{~K}$ as the distance between sources is increased from 0 to $10 \mathrm{~mm}$. As the separation between the sources is increased, the source on the right gets closer to the condenser, explaining this drop in maximum temperature. This temperature dependence with respect to the location of the heat source with respect to the condenser illustrates the importance of axial diffusion through the wall and wick.

The axial variation of the liquid and vapor pressure drop at the interface at a steady state is shown in Fig. 21. Once steady state is reached, irrespective of the location of the maximum temperature (and the maximum interface velocity), the maximum pressure drops in the liquid and vapor always occur near the left end of the evaporator. This is because of the significant velocities in the liquid and vapor encountered under the conditions of the present
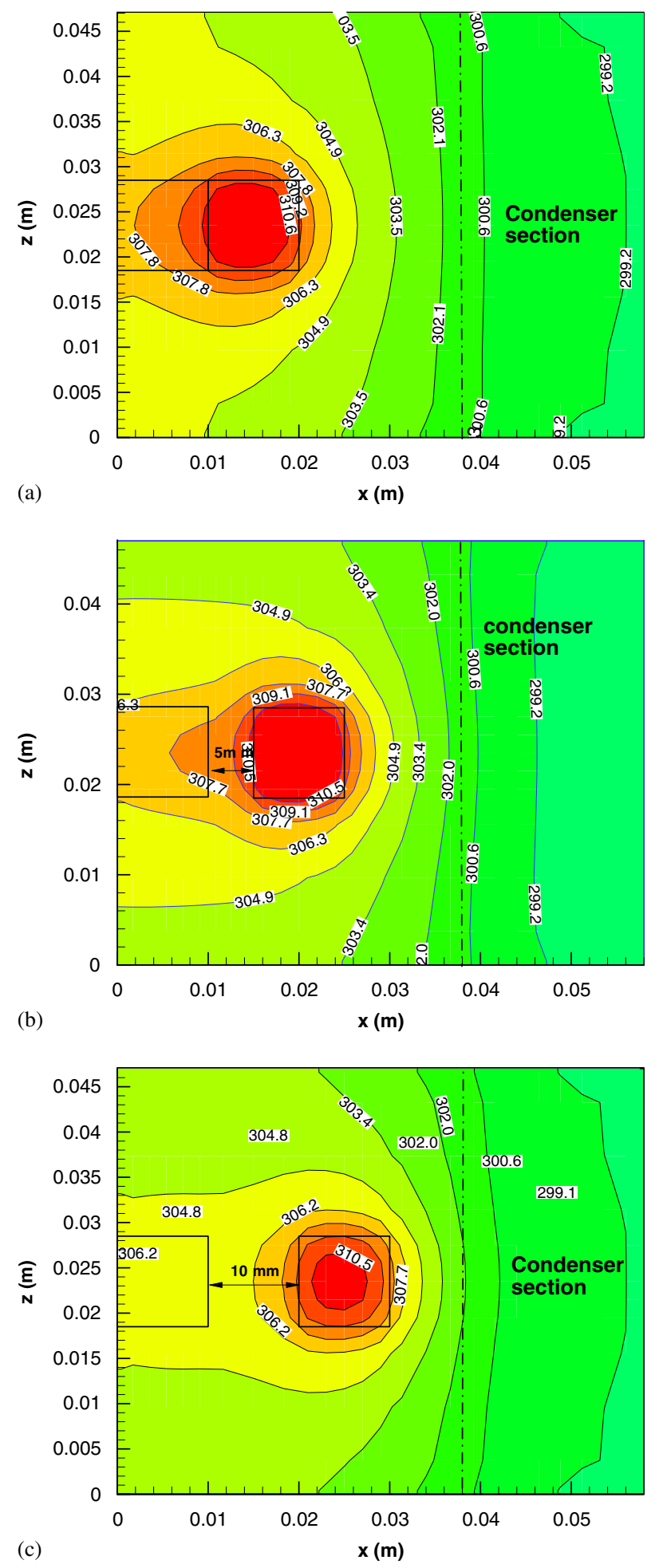

Fig. 20. Temperature contours in the liquid at the liquid-vapor interface for different separation between the heaters (heat input $=5-25 \mathrm{~W}$ ) [51].

work, which lead to high dynamic pressure losses. In the absence of gravity, the sum of the liquid and vapor pressure drops give the total pressure drop at any axial location along the liquid-vapor interface.

From Fig. 21 it is possible to determine the required capillary pressure drop by summing the maximum liquid 


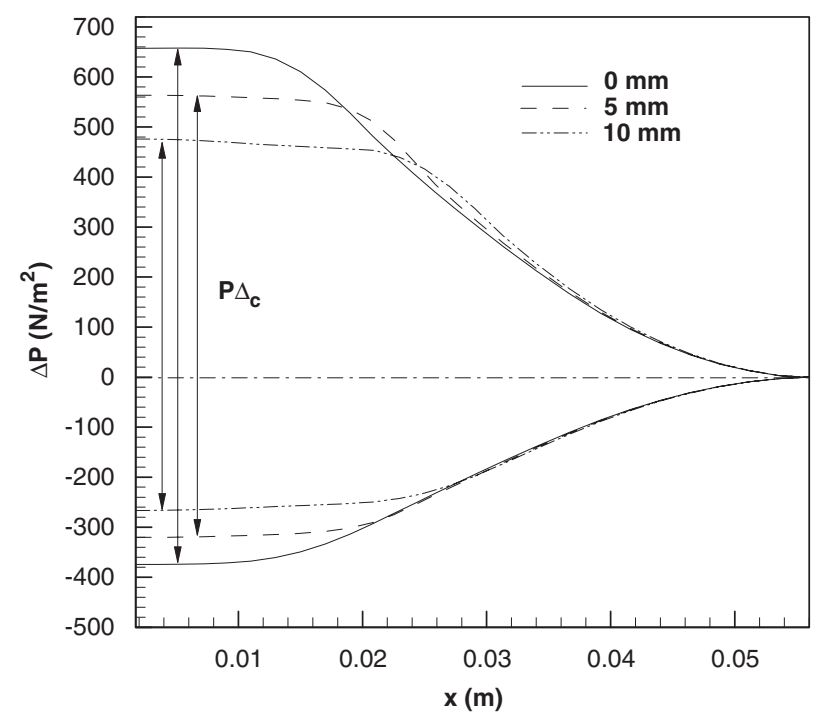

Fig. 21. Pressure drop in the liquid and vapor at the liquid-vapor interface at different heat source separation distances (heat input $5-25 \mathrm{~W}, z /$ $W=0.5)[51]$.

and vapor pressure drops. From the expression for the capillary pressure drop, $\Delta P_{\mathrm{c}}=2 \sigma / r_{\mathrm{p}}$, it is possible to determine the pore radius of the wick that can provide the required capillary pressure drop necessary to prevent dryout. For a given pore radius, the analysis helps to determine the time and location of dryout. The location of dryout is that at which the capillary pressure head has a maximum value.

This analysis highlights the importance of considering axial diffusion through the wall and wick in determining the temperature distribution in flat heat pipes. As the distance between multiple discrete heat sources increases, the maximum temperature in the flat heat pipe decreases, resulting in lower liquid and vapor pressure drops.

\section{Phase change energy storage}

One of the more attractive thermal management tools, particularly for applications where the transient is short and heat dissipation is periodic, is the use of phase change materials (PCMs). Examples for such applications include power electronics [52,53], spacecraft applications [54], wearable and portable computers [55], thermal control [56], and backup cooling units. Advanced hybrid cooling technologies for transient applications can be developed by combining phase change materials with other heat sinks, where the conventional heat sinks provide cooling during normal operation and the phase change materials augment the cooling capacity during power surges.

Power pulses for short periods occur in power semiconductors due to the current in-rush needed to start a motor, in inductive devices such as heaters and transformers, in capacitive charging, and in power grid management. The general approach for managing these transient spikes has been to use solid copper heat sinks to absorb the

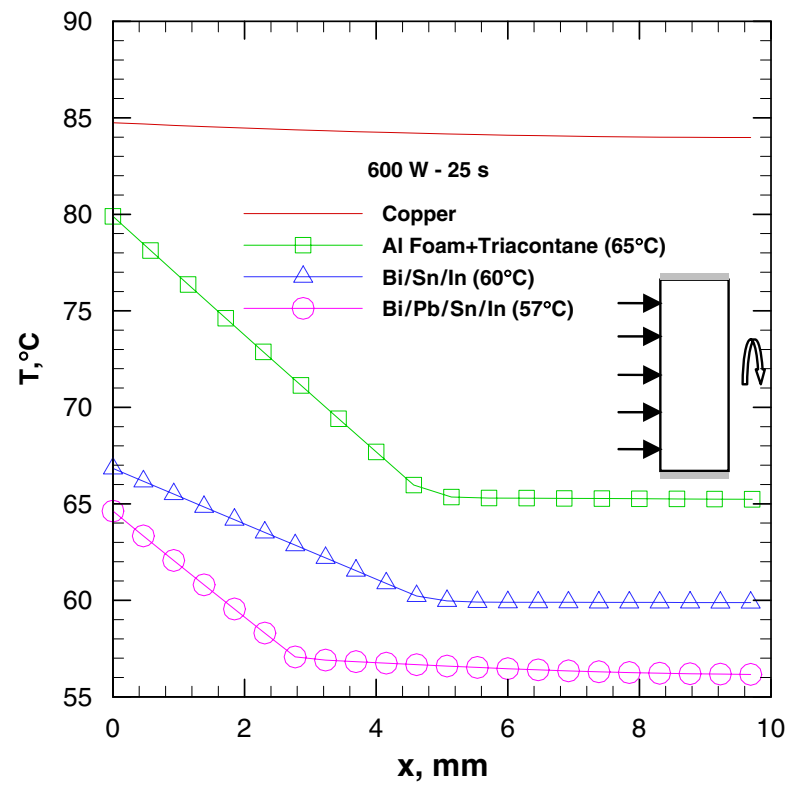

Fig. 22. Temperature distribution at $25 \mathrm{~s}$ (end of the pulse) for a $600 \mathrm{~W}$ pulse input for a copper heat sink, $\mathrm{Bi} / \mathrm{Pb} / \mathrm{Sn} / \mathrm{In}, \mathrm{Bi} / \mathrm{Sn} / \mathrm{In}$, and triacontane with a aluminum foam [58].

thermal transients. Use of a PCM energy storage unit as an alternative to the copper heat sinks has the potential to lower junction temperatures, while at the same time yielding weight and volume savings. Since the thermal transients in these applications last only for short periods, the PCM has a chance to recharge (solidify) between pulses [57].

Fig. 22 shows the temperature distribution in a solid heat sink compared to a PCM unit for use in power semiconductors for a typical power input of $600 \mathrm{~W}$, at the end of a power pulse [58]. The duration of the pulse is $25 \mathrm{~s}$. The performance of different PCMs (organic and metallic alloys) is compared against the performance of solid copper (not undergoing phase change). Since the thermal conductivity of organic PCMs is small $(O(0.1))$ compared to metallic alloys, a porous aluminum foam was introduced to enhance the effective thermal conductivity of the triacontane. Heat transfer in metallic foams has been studied in the literature (e.g., [59]). It can be seen from Fig. 22 that use of a PCM results in significant suppression of temperature at the junction compared with a copper heat sink. For example, the junction temperature for $\mathrm{Bi} / \mathrm{Pb} / \mathrm{Sn} / \mathrm{In}$ is $65^{\circ} \mathrm{C}$ while that for copper heat sink is $85^{\circ} \mathrm{C}$. In addition, at the end of the pulse, only the first $3 \mathrm{~mm}$ of the $\mathrm{Bi} / \mathrm{Pb} / \mathrm{Sn} / \mathrm{In}$ has melted, pointing to the possibility of a significant reduction in the volume required for a PCM unit (from the $10 \mathrm{~mm}$ thickness for the copper heat sink to approximately $3 \mathrm{~mm}$ for the PCM unit).

The choice between a conventional heat sink and PCMbased heat sinks can be made using the expression

$$
\frac{\left(T_{\text {junction }}(t)-T_{\text {melt }}\right)_{\mathrm{PCM}}}{\left(T_{\text {junction }}(t)-T_{\infty}\right)_{\text {Metal }}}=q^{\prime \prime} L \frac{\left(\rho C_{p}\right)_{\text {Metal }}}{(k \rho \Delta \mathrm{H})_{\mathrm{PCM}}}\left(1-\frac{t_{m}}{t}\right)
$$


where $T_{\text {junction }}$ is the junction temperature, $T_{\text {melt }}$ is the melting point, $T_{\infty}$ is the ambient temperature, $q^{\prime \prime}$ is the heat transfer per unit area, $L$ is the length of the PCM unit, $\rho$ is the density, $C_{\mathrm{p}}$ is the specific heat, $\Delta \mathrm{H}$ is the latent heat of fusion, $k$ is the thermal conductivity, $t$ is the time and $t_{\mathrm{m}}$ is the time taken by the PCM to reach melting point from its initial temperature. If the value of this ratio is less than 1, then the PCM unit will perform better than a conventional heat sink, in terms of suppression of junction temperature. Approximate estimates of volume savings derived from substituting PCMs for conventional metallic heat sinks can be obtained using the following expression:

$\frac{V_{\mathrm{PCM}}}{V_{\text {Metal }}} \sim \frac{\left[\rho C_{p}\left(T_{\text {junction }}-T_{\infty}\right)\right]_{\text {Metal }}}{\left[\rho\left(C_{p}\left(T_{\text {melt }}-T_{\infty}\right)+\Delta \mathrm{H}\right)\right]_{\mathrm{PCM}}}$

Alternatively, PCMs can be used with conventional parallel plate heat sinks for a number of electronics thermal management applications which encounter time-dependent cooling conditions such that the cooling rate periodically changes between high and low values. Fig. 23 shows a schematic of the hybrid heat sink unit proposed by Krishnan et al. [60]. The heat sink consists of a parallel plate heat sink with a portion of the fin tips immersed in a suitable phase change material. The fins dissipate heat through their exposed area during periods of high convective air cooling. The PCM at the fin tips participates by absorbing heat when the convective cooling rate is reduced $\left(h_{\text {low }}\right)$. The heat stored in the PCM is rejected to the ambient during the subsequent jump in convection in the next cycle. The advantage of the proposed arrangement is that it can dissipate heat continuously during both 'on' and 'off' periods.

In Fig. 24, the temporal evolution of heat transfer rates dissipated by a single fin for two different PCMs (paraffin and metallic alloys) with a $47^{\circ} \mathrm{C}$ melting point used at the tip is shown for a complete cycle of operation. Also included in this figure is the case where the entire length of the fin is exposed to air, and no PCM is used. The total length of the fin is $100 \mathrm{~mm}$, of which $30 \mathrm{~mm}$ is immersed in the PCM. The base temperature was maintained constant at $85^{\circ} \mathrm{C}$ throughout the calculations. An ambient heat transfer coefficient of $20 \mathrm{~W} / \mathrm{m}^{2} \mathrm{~K}$ was maintained for the first $600 \mathrm{~s}$, and then increased to $125 \mathrm{~W} / \mathrm{m}^{2} \mathrm{~K}$, allowing the PCM to re-solidify. For the first $600 \mathrm{~s}$, with the heat

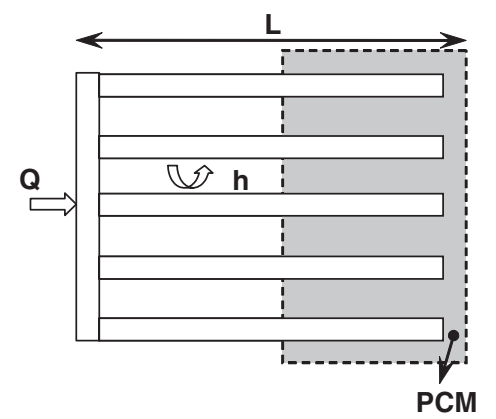

Fig. 23. A schematic of the hybrid heat sink [60].

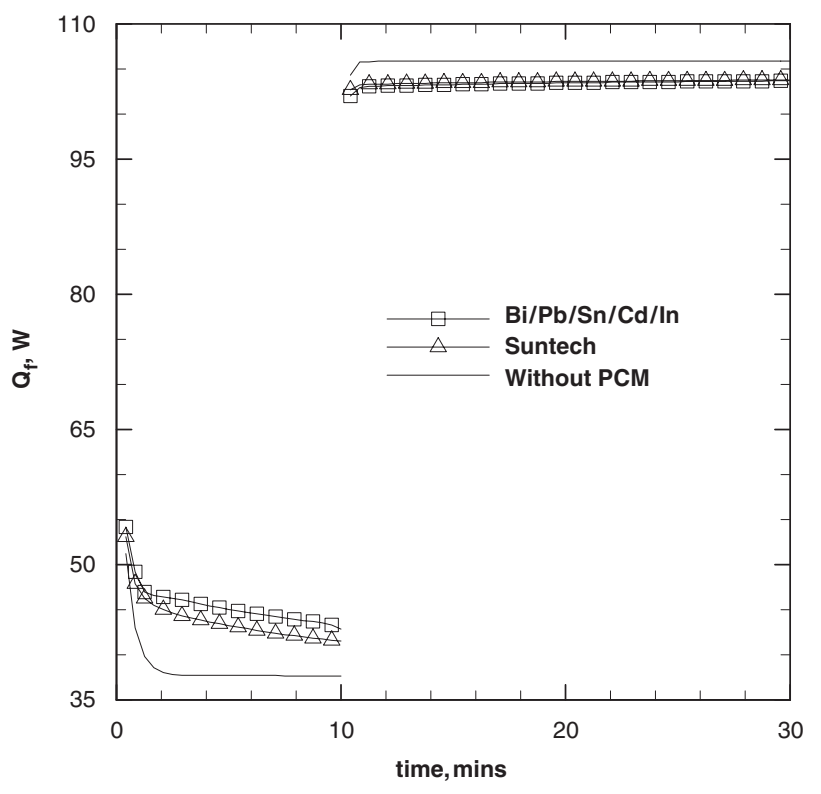

Fig. 24. Fin heat transfer rate as a function of time [60].

transfer coefficient at $20 \mathrm{~W} / \mathrm{m}^{2} \mathrm{~K}$ and ambient temperature being $35^{\circ} \mathrm{C}$, the fins with the PCM performed better than those without PCM. During this period, the fin heat transfer rate drops as time evolves because more PCM melts. Fig. 24 also shows a steep decrease in the heat transfer rate initially due to the sensible heating of the PCM from the initial temperature to the melting point of the PCM $\left(35-47^{\circ} \mathrm{C}\right)$. After $9 \mathrm{~min}$, the fin immersed in metallic alloy is able to dissipate $6 \mathrm{~W}(\sim 15 \%)$ more than the baseline case of no PCM; the paraffin was similarly able to dissipate $4.2 \mathrm{~W}(\sim 11 \%)$ more than the baseline case. During resolidification in contrast, although the fins with PCMs dissipate less heat than the fin without PCM (due to the resistance to heat flow posed by the PCM), the difference is not as pronounced as during the melting period. Moreover this difference diminishes as the solid grows and the heat transfer rate with the PCM increases.

Though organic phase change materials (e.g., paraffin) have very high latent heats of melting $\left(\geqq 10^{5} \mathrm{~J} / \mathrm{kg}\right)$ and isobaric specific heat capacities ( $\geqq 1000 \mathrm{~J} / \mathrm{kgK}$ ), they suffer from very low thermal conductivities $(\leq 0.1 \mathrm{~W} / \mathrm{mK})$. For transient applications where faster dissipation of heat is required, the effective thermal conductivity (thermal response) of the PCM unit must be increased if the high latent heat of absorption and specific heat are to be exploited. The effective thermal conductivity of the PCM can be improved with internal fins, metal filler particles, and metal foams. Local thermal equilibrium between the solid metal foam and the PCM is not ensured in such systems since their thermal diffusivities are very different. The use of a single volume-averaged energy equation for both the phases cannot be justified in such situations. A two-medium approach should be used instead to account for the local thermal non-equilibrium [61,62]. 


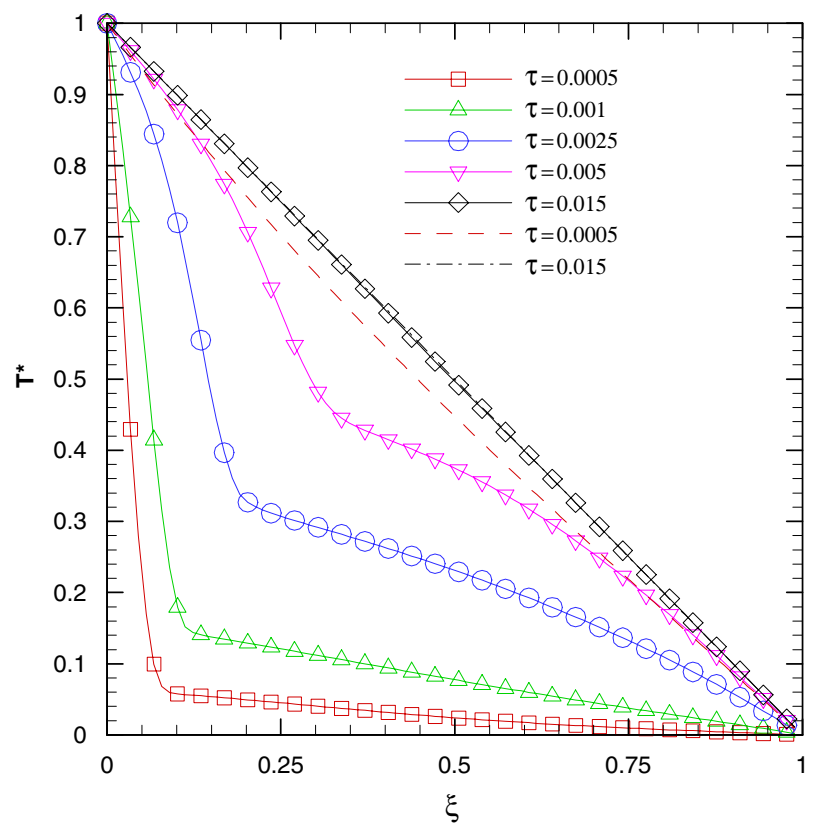

Fig. 25. Metal foam (broken lines without symbols) and fluid (solid lines with symbols) temperature distributions along the mid-height of the domain for $\mathrm{Ra}=10^{6}, \mathrm{Da}=10^{-2}$ and $\operatorname{Pr}=1$ at various non-dimensional times. Note that metal foam reaches a steady state very fast compared to the fluid [61].

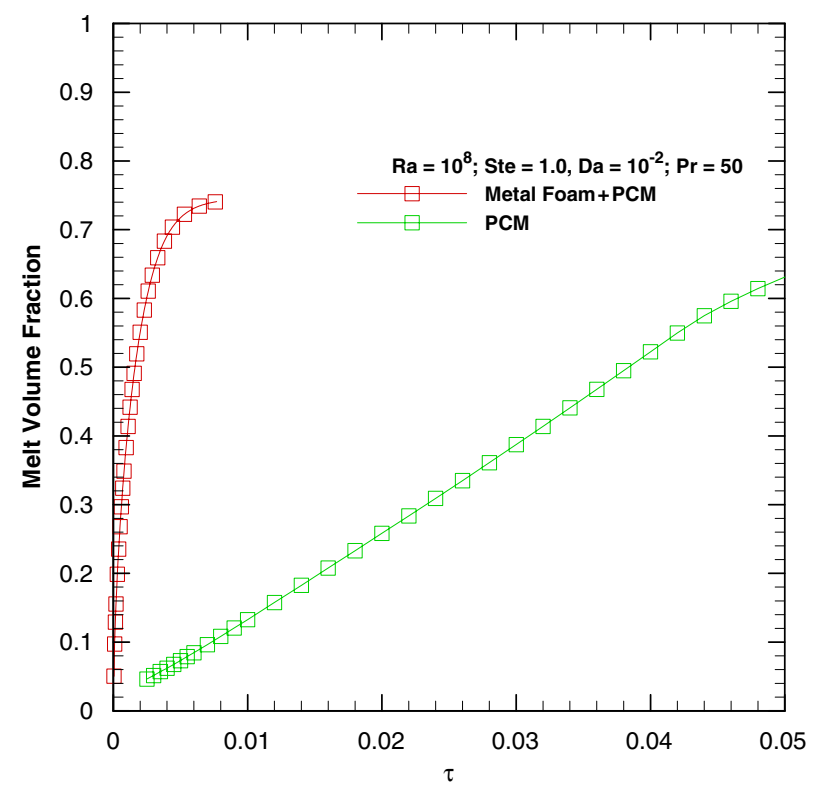

Fig. 26. Temporal evolution of melt volume fraction (melting rate) for $\mathrm{Ra}=10^{8}, \mathrm{Da}=10^{-2}, \mathrm{Ste}=1$ and $\operatorname{Pr}=50$ for PCM with and without metal foams [62].

Fig. 25 illustrates the thermal non-equilibrium in metal foam and fluid (air) system for pure natural convection domain [61]. The calculations were performed for a square enclosure with the vertical walls maintained at two different end temperatures. The walls were isolated from each other by adiabatic horizontal walls. The figure shows the temperature distribution of the metal foam and fluid at the mid-height of the square domain for various dimensionless times. It can be seen that the metal foam reaches a steady state even before the fluid starts develop. In situations such as these, equilibrium models would not capture the transient behavior of these systems because of the assumption of local thermal equilibrium.

Fig. 26 shows the melting rates for phase change materials with and without metal foams incorporated [62]. It can be clearly seen that the inclusion of metal foam increases the melting rate. The metal foam-integrated PCM unit reaches a steady state almost one order of magnitude earlier in time than the PCM unit without foam (in the figure, only a part of the curve for the PCM without foam is included for clarity).

\section{Miniature piezoelectric fans}

A novel cooling technology studied extensively by the author's group utilizes the vibration of piezoceramic materials to create air movement for cooling [63]. This technology is desirable because it is noiseless at the frequencies of operation, consumes very little power, and is compact, lightweight, and durable.

A piezoelectric fan is fabricated by bonding a piezoelectric patch or several patches to a shim material cut to the desired shape and size, or by using the patch itself with no shim attached. When an alternating voltage is applied to the piezoelectric patch, it expands and contracts alternately with the same frequency as the input signal. When attached to a shim material, the shim flaps back and forth like a hand-held fan, albeit much faster.

The alternating voltage is applied at a resonant frequency of the piezoelectric fan to maximize fan efficiency and tip deflection. To ensure silent operation, the fans are designed such that their first mode of resonance is outside the range of frequencies audible to the human ear. Fans operating at frequencies less than $100 \mathrm{~Hz}$ are referred to as infrasonic, while fans operating at frequencies greater than $20 \mathrm{kHz}$ are dubbed ultrasonic in this work.

Flow visualization experiments were conducted to gain insight into the flow produced by piezoelectric fans [64]. In one experiment, a fan was placed inside a clear acrylic enclosure and the air was seeded with smoke and illuminated with an Argon-ion laser sheet. The fan was then actuated at its first resonant frequency of $20 \mathrm{~Hz}$ and the resulting fluid movement was recorded with a digital video camera. Fig. 27 shows the flow field development after the fan is turned on at $t=0 \mathrm{~s}$. Vortices being shed from the tip of the fan are marked as A and B in the figure. By $t=15 / 30 \mathrm{~s}$, the flow is fully developed within the enclosure.

Additional visualization experiments were conducted to compare the two-dimensional flow patterns resulting from the resonant vibration of a baffled piezoelectric fan to results predicted by numerical simulation [65]. The piezoelectric fan was sandwiched between a black bottom 

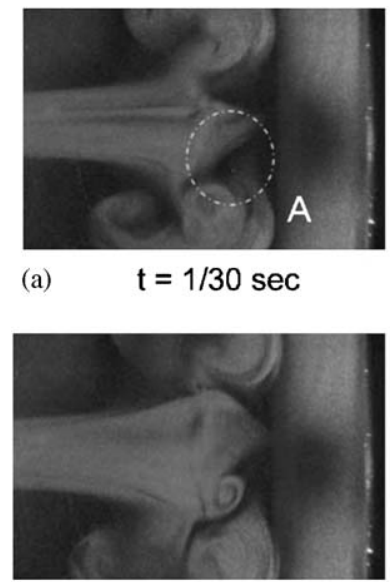

(c) $t=5 / 30 \mathrm{sec}$ (a) $t=1 / 30 \mathrm{sec}$
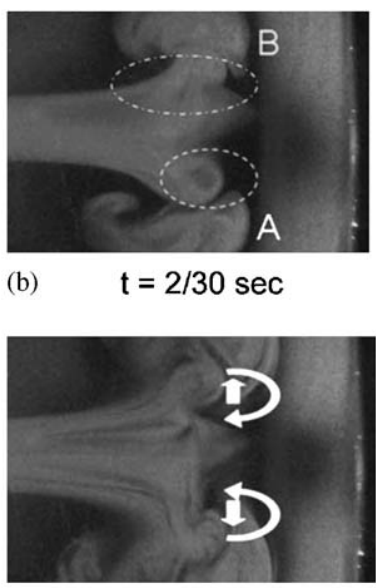

(d) $\mathrm{t}=15 / 30 \mathrm{sec}$ (b) $\quad t=2 / 30 \mathrm{sec}$

Fig. 27. Transient flow field from near-boundary flow visualization experiments for the infrasonic piezoelectric fan, at times of (a) $1 / 30$, (b) $2 / 30$, (c) $5 / 30$ and (d) $15 / 30 \mathrm{~s}$. The fan blade position is shown in (a) [64].

surface and a transparent acrylic top sheet, with the side walls in the experiment being distant enough from the fan to have minimal interference effects on the flow field. The fan was located at the center of the domain and a baffle was placed along the axis of the fan spanning the full length of the setup. A laser sheet illuminated the field from the side, parallel to the top plexiglass surface, and smoke from a theatrical fog generator was used to seed the flow. A digital video camera was placed above the setup to capture the scattered light from the smoke particles in the domain.

The results of the numerical simulation based on acoustic streaming [66] and the experimental visualization are compared in Fig. 28. The agreement between experiment and theory is seen to be quite good, although the size and location of the outer streaming nodes are slightly different from predicted values. The main sources of the differences between model and experiment can be attributed to the following reasons: the assumption of twodimensional flow in the model; the baffle used in the experiments not being ideal; errors in the model related to perturbation and incompressibility assumptions; and errors resulting from the numerical methods employed.

The flow visualization experiments offered promising evidence that piezoelectric fans could be used to enhance heat transfer in electronic systems. The thermal performance of piezoelectrically actuated, vibrating beams has been investigated in many different experiments [64,67-69]. One particular experiment showed the enhancement in heat transfer that could be obtained by implementing piezoelectric fans in a cell phone enclosure [64].

A fan with a resonant frequency of $20 \mathrm{~Hz}$ was placed in an enclosure similar in size to a cell phone. The enclosure was open on either end to provide an inlet and outlet for the air flow, though the inlet of the enclosure was partially blocked by the clamp of the piezoelectric fan. A heat source attached to an aluminum heat sink was also placed in the enclosure with the piezoelectric fan. All other surfaces were insulated using polystyrene foam to simulate adiabatic
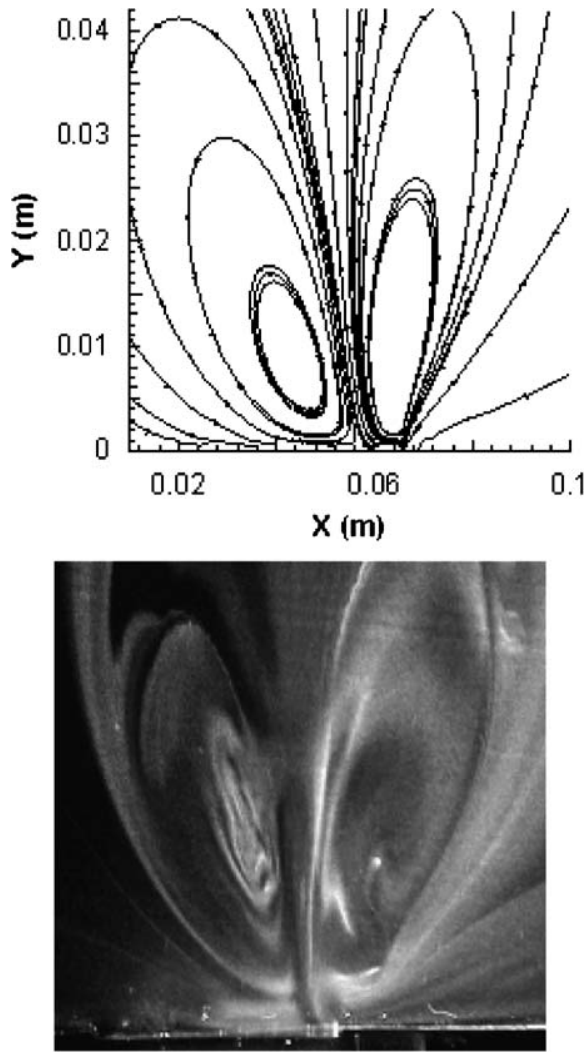

Fig. 28. Comparison between computed time-averaged first order flow (top) and experimental flow visualization (bottom) for a baffled piezoelectric fan vibrating in an infinite medium [65].

boundary conditions. The piezoelectric fan was tested first in a vertical orientation (stroke being from side to side), and then in a horizontal orientation (stroke being up and down) as shown in Fig. 29. The fan oriented in the vertical configuration was tested in three different positions and the fan in the horizontal orientation was tested in one position relative to the heat sink. Further details on the setup and configuration of this experiment are available in [64].

Under steady-state operating conditions, the convective heat transfer coefficients for natural convection, and with the fans placed in different positions over the heat sink were calculated using an energy balance between the power input and the heat removed from the surface of the heat source by convection according to:

$h=\frac{q}{A\left(T_{\text {chip }}-T_{\text {avg }}\right)}$

in which $q$ is the power input to the heat source, $A$ is the exposed surface area of the copper block (it may be noted that the heat transfer coefficient is always referenced to the surface area of the heat source, and not to that of the heat sink), and $T_{\text {avg }}$ is the average temperature from three thermocouples used to measure the air temperatures over the heat sink at different locations. Another thermocouple was used to monitor the temperature of the copper block heat source $\left(T_{\text {chip }}\right)$. 

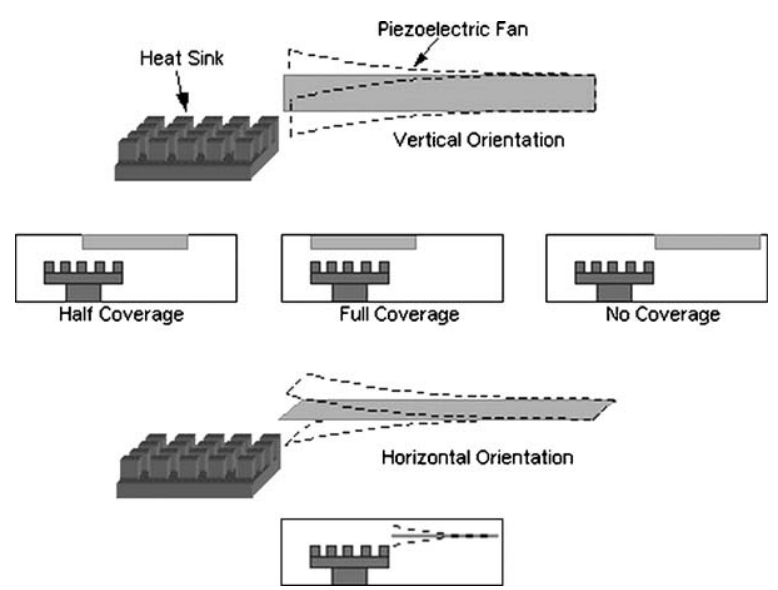

Fig. 29. Piezoelectric fan orientations used in the cell phone cooling experiment (Açıkalın et al., 2004).

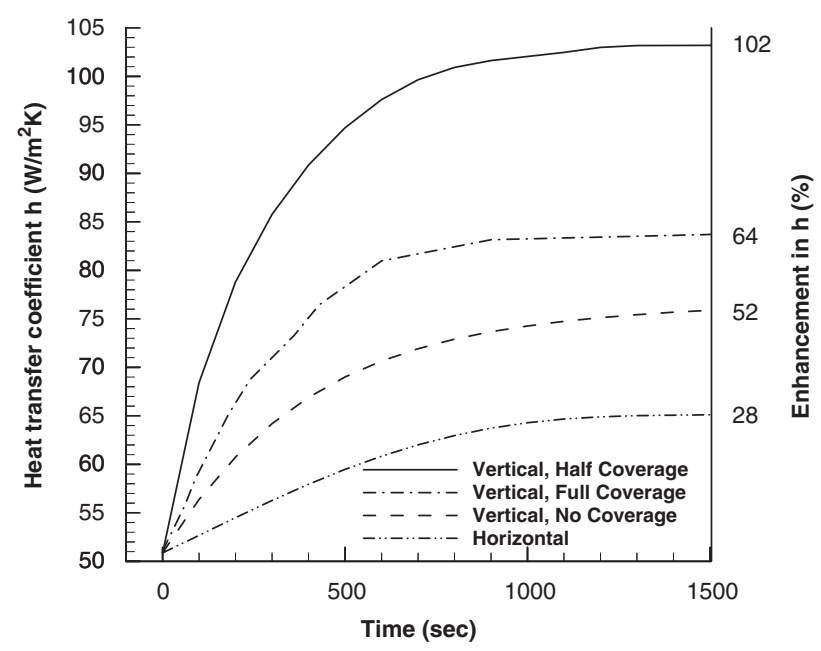

Fig. 30. Enhancement in heat transfer coefficient for the four different piezoelectric fan positions in the cell phone enclosure. At $t=0 \mathrm{~s}$, the piezoelectric fan inside the enclosure is turned on. The system reached a steady state by $1500 \mathrm{~s}$ [64].

The heat transfer coefficients for the four different piezoelectric fan positions studied are plotted in Fig. 30. The uncertainties in measured heat transfer coefficients were estimated to be under $8 \%$ for all the experiments. The largest heat transfer enhancement was obtained when the fan covered half of the heat sink. In this position there was more than a $100 \%$ increase in the heat transfer coefficient due to the fans, relative to natural convection alone. This implies that the heat transfer rate, in a setup such as the one under study, can be doubled (for instance, from $1 \mathrm{~W}$ in natural convection alone to $2 \mathrm{~W}$ with the fan) by a fan that has a power consumption of approximately $3 \mathrm{~mW}$.

In more recent work, Açıkalın et al. [70] have optimized piezoelectric fans for cooling light emitting diodes. The structural geometry and the dynamics of the piezoelectric fans have also been optimized [71,72].

Piezoelectric fans are a viable technology for meeting a variety of special cooling needs in electronic devices. They are small, noiseless, low-power devices, and can easily be fabricated to suit specific applications. They are not intended to replace rotary fans in larger devices, such as laptops and personal computers, but can provide supplemental cooling in hot spots and other stagnant areas where a rotary fan is ineffective. In smaller devices, where rotary fans are not practical and electronics are pushed to the limits of their heat dissipation capacities, piezoelectric fans offer a realistic cooling solution while meeting the noise and power requirements of portable devices.

\section{Thermal contact conductance}

All engineering surfaces exhibit some level of microscopic roughness. Resistance to heat flow through a contact interface exists because only a small portion, usually $1-2 \%$ [73], of the nominal surface area is actually in contact. This is the root cause of arguably the most ubiquitous and persistent problem in electronics packaging and a host of other thermal technologies, i.e., the existence of thermal contact resistance.

Heat may pass through the interface via three paths: conduction through the contact spots, conduction through the gas present in the gap between the surfaces, and radiation across the gap. Convection may be neglected due to the small length scales involved. Also, radiation does not play a significant role at temperatures below $500^{\circ} \mathrm{C}$ [74]. Since the conductivity of the gas is much smaller than that of the substrate, most of the heat is constrained to flow through the contact spots. This constriction and subsequent spreading of heat flow lines in the two materials in contact manifests as a thermal resistance at the interface. The total contact resistance of the surface is found by summing in parallel the constriction resistances of all of the contact spots.

The prediction of thermal contact conductance (inverse of resistance) is commonly accomplished through the use of semi-empirical correlations. With assumptions of a particular statistical distribution of surface parameters, as well as a mode of deformation for contacting asperities, contact conductance is predicted for given material properties and applied load [75]. Since the surface parameters such as asperity height, density, slope, and radius of curvature are not intrinsic properties of the surface, but instead can vary with the sampling frequency, the contact conductance predicted from these equations is dependent on the scanning instrument used.

More recent attempts at predicting thermal contact resistance at an interface, especially focusing on the low contact pressures allowable in electronics cooling, have taken advantage of the speed and processing power of modern computers to track the number of asperities in contact at a surface by directly using surface profile data $[76,77]$. Inputs to this model include the surface profiles, mechanical and thermal material properties, nominal contact area, and specified loads. The mode of deformation of each asperity is not assumed, but determined by guessing 


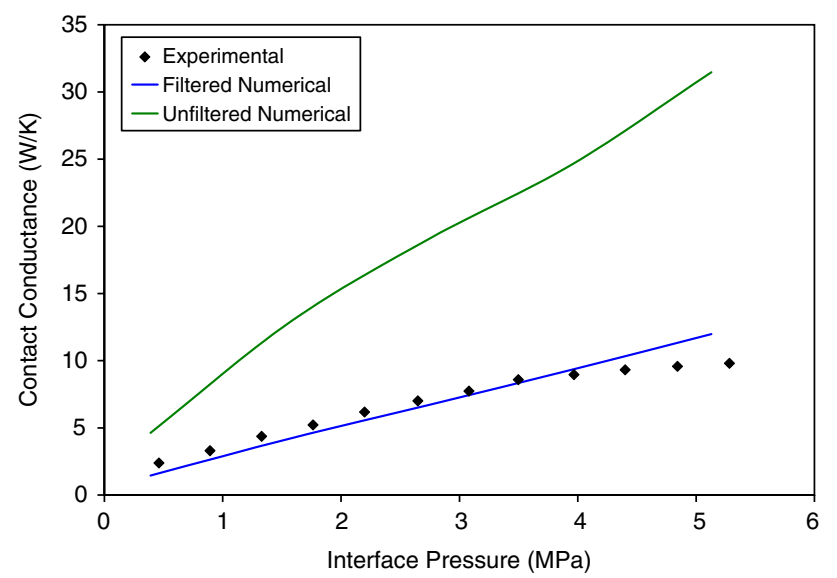

Fig. 31. Comparison of predictions to experimental measurements of contact conductance. The results are for contact between two aluminum surfaces with a $5 \mu \mathrm{m}$ center-line average surface roughness. The unfiltered data were taken with a sampling frequency of $640 / \mathrm{mm}$ and the filtered data have a low-pass cutoff wavelength of $19 \mu \mathrm{m}$.

the mean plane separation between the surfaces, calculating the pressure and area of each microscopic asperity in contact, and summing the contribution to the total load from each asperity. This iterative process is repeated at various assumed values of mean plane separation until the sum of the load contributions from individual asperities is within some tolerance of the specified nominal load. Once the deformation, and hence the geometry, of each asperity is known for a given contact pressure, the contact resistance may be calculated by summing all of the constriction resistances. One recent constriction resistance model [78] uses an improved geometrical shape for the asperities in contact. The resulting correlation takes into account the gas gap conductivity and is readily implemented in a computer algorithm.

The models described in Singhal and Garimella [76] and Black et al. [78] can be used in combination to predict the contact conductance at any surface. However, as with the semi-emprical correlation method, results from this prediction scheme are dependent on details of the number of asperities calculated and their geometry, which in turn is a function of the resolution of the scanning instrument used for surface characterization. This dependence may be handled by functional filtering, in which the data are filtered to the proper wavelengths involved in the physics of deformation. The long-wavelength cutoff is easily determined from the nominal area of contact, but there is no equally obvious choice for the short-wavelength cutoff. The short-wavelength cutoff is likely to be a function of the load and material properties, and of intrinsic surface properties which are independent of the scanning instrument. One technique for finding such intrinsic surface properties [79] involves using the structure function to characterize a surface. For a multi-fractal surface the transition between modes of surface preparation are marked by a particular frequency. Predictions for contact

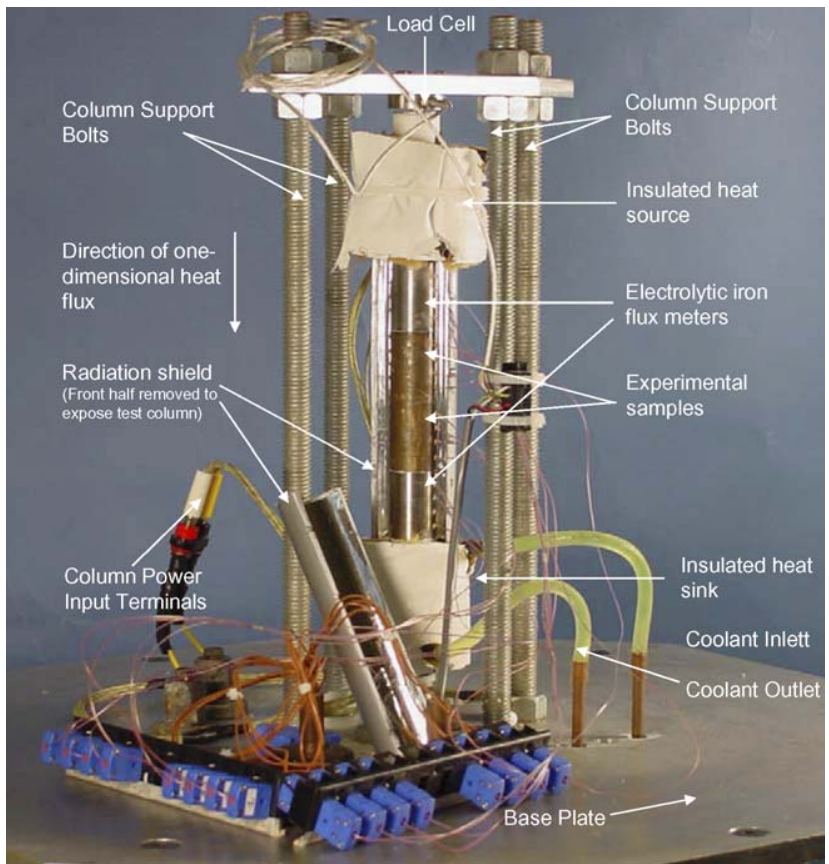

Fig. 32. Axial heat flow facility used in the experimental measurement of contact conductance.

conductance are obtained by passing the input profiles through a low-pass filter with a cutoff frequency equal to the transition frequency and using the computer algorithm already discussed. Results from the prediction using filtered and unfiltered surface profiles are shown in Fig. 31. The experimental measurements in Fig. 31 were obtained using the axial heat flow facility shown in Fig. 32.

The approach described has been successful in predicting contact conductance at the interface between metallic surfaces, as validated by comparison with experimental measurements. The current results are applicable, in particular, under situations where metal-to-metal contacts are encountered at high heat fluxes (RF transistors, power electronics components and others). Extensions to the model for handling non-metallic materials and more complex non-flat surface contact are in progress. This enhanced model may then be integrated with thermomechanical analyses of thermal interface materials (such as that of Singhal et al. [80], in which the volume and the distribution of highly conductive spheres dispersed in a soft matrix for thermal interface materials is optimized), to predict contact resistance across more complex interfaces.

\section{Other technologies}

Other promising technologies for compact cooling of electronics are being investigated by the author's group as well as by a number of other researchers worldwide. These include miniature refrigeration systems [81], use of carbon nanotubes in producing high-conductance interfaces $[82,83]$, and advanced thermoelectric materials $[84,85]$. These are not discussed here further due to limitations of space. 


\section{Closure}

A number of novel, high-performance cooling techniques for use in emerging electronics applications have been reviewed, with a focus on examples from the author's work. Microchannel transport and micropumping techniques, jet impingement, miniaturized heat pipes, transient phase change energy storage systems, smart piezoelectric fans, and enhancement of interface contact conductance are discussed, from an experimental as well as a theoretical modeling viewpoint.

\section{Acknowledgements}

Financial support from the National Science Foundation, Semiconductor Research Corp., Cray Research Inc., and members of the Cooling Technologies Research Center, an NSF Industry/University Cooperative Research Center at Purdue University, is gratefully acknowledged. Assistance from Shankar Krishnan, Dong Liu, Vishal Singhal, and Sydney Wait in the preparation of this article is greatly appreciated.

\section{References}

[1] S.V. Garimella, C.B. Sobhan, Transport in microchannels - a critical review, Annual Review of Heat Transfer 13 (2003) 1-50 (Chapter 1).

[2] C.B. Sobhan, S.V. Garimella, A comparative analysis of studies on heat transfer and fluid flow in microchannels, Microscale Thermophysical Engineering 5 (2001) 293-311.

[3] P.Y. Wu, W.A. Little, Measurement of friction factor for the flow of gases in very fine channels used for micro miniature Joule Thompson refrigerators, Cryogenics 23 (1983) 273-277.

[4] S.B. Choi, R.F. Barron, R.O. Warrington, Fluid flow and heat transfer in microtubes, Micromechanical Sensors, Actuators and Systems, ASME DSC 32 (1991) 123-134.

[5] X.F. Peng, G.P. Peterson, B.X. Wang, Frictional flow characteristics of water flowing through microchannels, Experimental Heat Transfer 7 (1994) 249-264.

[6] X.F. Peng, G.P. Peterson, B.X. Wang, Heat transfer characteristics of water flowing through microchannels, Experimental Heat Transfer 7 (1994) 265-283.

[7] D. Yu, R. Warrington, R. Barron, T. Ameel, An experimental and theoretical investigation of fluid flow and heat transfer in microtubes, ASME/JSME Thermal Engineering Conference 1 (1995) 523-530.

[8] P.Y. Wu, W.A. Little, Measurement of the heat transfer characteristics of gas flow in fine channel heat exchangers for micro miniature refrigerators, Cryogenics 24 (1984) 415-420.

[9] B.X. Wang, X.F. Peng, Experimental investigation on liquid forced convection heat transfer through microchannels, International Journal of Heat and Mass Transfer 37 (Suppl. 1) (1994) 73-82.

[10] X.F. Peng, G.P. Peterson, Convective heat transfer and flow friction for water flow in microchannel structures, International Journal of Heat and Mass Transfer 39 (1996) 2599-2608.

[11] T.M. Adams, S.I. Abdel-Khalik, S.M. Jeter, Z.H. Qureshi, An experimental investigation of single-phase forced convection in microchannels, International Journal of Heat and Mass Transfer 41 (1998) 851-857.

[12] D. Liu, S.V. Garimella, Investigation of liquid flow in microchannels, AIAA Journal of Thermophysics and Heat Transfer 18 (2004) 65-72.

[13] P.-S. Lee, S.V. Garimella, D. Liu, Investigation of heat transfers in rectangular microchannels, International Journal of Heat and Mass Transfer 48 (2005) 1688-1704.
[14] S.V. Garimella, V. Singhal, Single-phase flow and heat transport and pumping considerations in microchannel heat sinks, Heat Transfer Engineering 25 (2004) 15-25.

[15] V. Singhal, S.V. Garimella, A. Raman, Microscale pumping technologies for microchannel cooling systems, Applied Mechanics Reviews 57 (2004) 191-221.

[16] D.J. Schlitz, S.V. Garimella, T.S. Fisher, Numerical Simulation of Microscale ion Driven Air Flow ASME International Mechanical Engineering Congress and Exposition, IMECE2003-41316, Washington, DC, November, 2003.

[17] M. Robinson, Movement of air in the electric wind of the corona discharge, Transactions of the American Institute of Electrical Engineers pp. (1961) 143-150.

[18] S. Ahn, Y. Kim, Fabrication and experiment of a planar micro ion drag pump, Sensors and Actuators A (Physical), A 70 (1998) 1-5.

[19] V. Singhal, S.V. Garimella, A novel valveless micropump with electrohydrodynamic enhancement for high heat flux cooling, IEEE Transactions on Advanced Packaging 28 (2005) 216-230.

[20] V. Singhal, S.V. Garimella, Influence of bulk fluid velocity on the efficiency of electrohydrodynamic pumping, ASME Journal of Fluids Engineering 127 (2005) 484-494.

[21] E. Stemme, G. Stemme, A valveless diffuser/nozzle-based fluid pump, Sensors and Actuators A: Physical 39 (1993) 159-167.

[22] J. Seyed-Yagoobi, J.C. Chato, J.M. Crowley, P.T. Krein, Induction electrohydrodynamic pump in vertical configuration, Part 1- Theory, ASME Journal of Heat Transfer 111 (1989) 664-669.

[23] S.F. Bart, L.S. Tavrow, M. Mehregany, J.H. Lang, Microfabricated electrohydrodynamic pumps, Sensors and Actuators A: Physical 21-23 (1990) 193-197.

[24] V. Singhal, S.V. Garimella, J.Y. Murthy, Low Reynolds number flow through nozzle-diffuser elements in valveless micropumps, Sensors and Actuators A 113 (2004) 226-235.

[25] D. Liu, S.V. Garimella, S.T. Wereley, Infrared micro-particle image velocimetry measurement in silicon-based microdevices, Experiments in Fluids 38 (2005) 385-392.

[26] S.V. Garimella, Heat transfer and flow fields in confined jet impingement, Annual Review of Heat Transfer XI (2000) 413-494.

[27] D.J. Womac, S. Ramadhyani, F.P. Incropera, Correlating equations for impingement cooling of small heat sources with single circular liquid jets, Journal of Heat Transfer 115 (1993) 106-115.

[28] N.T. Obot, W.J.M. Douglas, A.S. Mujumdar, Effect of Semiconfinement on Impingement Heat Transfer, Proceedings of the 7th International Heat Transfer Conference 3 (1982) 395-400.

[29] S.V. Garimella, R.A. Rice, Confined and submerged liquid jet impingement heat transfer, ASME Journal of Heat Transfer 117 (1995) 871-877.

[30] V.P. Schroeder, S.V. Garimella, Heat Transfer from a Discrete Heat Source in Confined Air Jet Impingement, Proceedings of the International Heat Transfer Conference, Brighton, England, Vol. 5, 1998, pp. 451-456.

[31] S.V. Garimella, B. Nenaydykh, Nozzle-geometry effects in liquid jet impingement heat transfer, International Journal of Heat and Mass Transfer 39 (1996) 2915-2923.

[32] C.-Y. Li, S.V. Garimella, Prandtl-number effects and generalized correlations for confined and submerged jet impingement, International Journal of Heat and Mass Transfer 44 (2001) 3471-3480.

[33] N.T. Obot, T.A. Trabold, Impingement heat transfer within arrays of circular jets: Part 1-Effects of minimum, intermediate, and complete crossflow for small and large spacings, Journal of Heat Transfer 109 (1987) 872-879.

[34] A.M. Huber, R. Viskanta, Effect of jet-jet spacing on convective heat transfer to confined, impinging arrays of axisymmetric air jets, International Journal of Heat and Mass Transfer 37 (1994) 2859-2869.

[35] S.V. Garimella, V.P. Schroeder, Local heat transfer distributions in confined multiple air jet impingement, ASME Journal of Electronic Packaging 123 (2001) 165-172.

[36] J.A. Fitzgerald, S.V. Garimella, Flow field effects on heat transfer in confined jet impingement, ASME Journal of Heat Transfer 119 (1997) 630-632. 
[37] J.A. Fitzgerald, S.V. Garimella, A study of the flow field of a confined and submerged impinging jet, International Journal of Heat and Mass Transfer 41 (1998) 1025-1034.

[38] Y.-J. San, C.H. Huang, M.-H. Shu, Impingement cooling of a confined circular air jet, International Journal of Heat Mass Transfer 40 (1997) 1355-1364.

[39] S. Polat, Heat and mass transfer in impingement drying, International Journal of Drying Technology 11 (1993) 1147-1176.

[40] G.K. Morris, S.V. Garimella, Orifice and impingement flow fields in confined jet impingement, Journal of Electronic Packaging 120 (1998) $68-72$.

[41] G.K. Morris, S.V. Garimella, J.A. Fitzgerald, Flow-field prediction in submerged and confined jet impingement using the Reynolds stress model, ASME Journal of Electronic Packaging 121 (1999) 255-262.

[42] G.K. Morris, S.V. Garimella, R.S. Amano, Prediction of jet impingement heat transfer using a hybrid wall treatment with different turbulent Prandtl number functions, ASME Journal of Heat Transfer 118 (1996) 562-569.

[43] S.V. Garimella, Enhanced air cooling of electronic equipment, in: S.J. Kim, S.W. Lee (Eds.), Air Cooling Technology for Electronic Equipment, CRC Press, 1996 Chapter 6.

[44] S.V. Garimella, Recent developments in high-performance cooling techniques for electronic systems, in: J.P. Bardon, et al. (Eds.), Thermal Management of Electronic Systems III, Elsevier, Paris, 1997, pp. 3-15.

[45] P.F. Sullivan, S. Ramadhyani, F.P. Incropera, Use of smooth and roughened spreader plates to enhance impingement cooling of small heat sources with single circular liquid jets, Topics in Heat Transfer, HTD 206-2 (1992) 103-110.

[46] L.A. Brignoni, S.V. Garimella, Experimental optimization of confined air jet impingement on a pin fin heat sink, IEEE Transactions on Components and Packaging Technologies 22 (1999) 399-404.

[47] H.A. El-Sheikh, S.V. Garimella, Enhancement of air jet impingement heat transfer using pin-fin heat sinks, IEEE Transactions on Components and Packaging Technologies 23 (2000) 300-308.

[48] H.A. El-Sheikh, S.V. Garimella, Heat transfer in multiple air jet impingement using pin-fin heat sinks, IEEE Transactions on Advanced Packaging 23 (2000) 113-121.

[49] S.V. Garimella, C.B. Sobhan, Recent advances in the modeling and applications of nonconventional heat pipes, Advances in Heat Transfer 35 (2001) 249-308 (Chapter 4).

[50] U. Vadakkan, J.Y. Murthy, S.V. Garimella, Transient Analysis of Flat Heat Pipes ASME Summer Heat Transfer Conference, HT200347349, Las Vegas, Nevada, July 21-23, 2003.

[51] U. Vadakkan, S.V. Garimella, J.Y. Murthy, Transport in flat heat pipes at high heat fluxes from multiple discrete sources, ASME Journal of Heat Transfer 126 (2004) 347-354.

[52] A.G. Evans, M.Y. He, J.W. Hutchinson, M. Shaw, Temperature distribution in advanced power electronics and the effect of phase change materials on temperature suppresion during power pulses, ASME Journal of Electronics Packaging 123 (2001) 211-217.

[53] T.J. Lu, Thermal management of high power electronics with phase change cooling, International Journal of Heat and Mass Transfer 34 (2000) 2245-2256.

[54] D.C. Price, A review of selected thermal management solutions for military electronic systems, IEEE CPMT 26 (2003) 26-39.

[55] E.M. Alawadhi, C.H. Amon, Thermal analyses of a PCM thermal control unit for portable electronic devices: experimental and numerical studies, IEEE CPMT 26 (2003) 116-125.

[56] D. Pal, Y. Joshi, Application of phase change materials to thermal control of plastic quad packages: a computational study, Numerical Heat Transfer 30A (1996) 19-34.

[57] S. Krishnan, S.V. Garimella, Analysis of a phase change energy storage system for pulsed power dissipation, IEEE Transactions on Components and Packaging Technologies 27 (2004) 191-199.

[58] S. Krishnan, S.V. Garimella, Thermal management of transient power spikes in electronics - phase change energy storage or copper heat sinks?, ASME Journal of Electronic Packaging 126 (2004) $308-316$

[59] T.J. Lu, H.A. Stone, M.F. Ashby, Heat transfer in open-cell metal foams, Acta Materialia 46 (1998) 3619-3635.

[60] S. Krishnan, S.V. Garimella, S.S. Kang, A novel hybrid heat sink using phase change materials for transient thermal management of electronics, IEEE Transactions on Components and Packaging Technologies 28 (2005) 281-289.

[61] S. Krishnan, J.Y. Murthy, S.V. Garimella, A two-temperature model for the analysis of passive thermal control systems, ASME Journal of Heat Transfer 126 (2004) 628-637.

[62] S. Krishnan, J.Y. Murthy, S.V. Garimella, A two-temperature model for solid/liquid phase change in metal foams, ASME Journal of Heat Transfer, Vol. 127 pp. 995-1004, 2005.

[63] M. Toda, Theory of air flow generation by a resonant type PVF2 bimorph cantilever vibrator, Ferroelectrics 22 (1979) 911-918.

[64] T. Açıkalın, S.M. Wait, S.V. Garimella, A. Raman, Experimental investigation of the thermal performance of piezoelectric fans, Heat Transfer Engineering 25 (2004) 4-14.

[65] T. Açıkalın, A. Raman, S.V. Garimella, Two-dimensional streaming flows induced by resonating thin beams, Journal of the Acoustical Society of America 114 (2003) 1785-1795.

[66] W.L. Nyborg, Acoustic streaming near a boundary, Journal of Acoustical Society of America 30 (1958) 329-339.

[67] S. Wait, T. Açıkalın, S.V. Garimella, A. Raman, Piezoelectric Fans for the Thermal Management of Electronics Proceedings of the Sixth ISHMT/ASME Heat and Mass Transfer Conference, Kalpakkam, India, Paper No. HMT-2004-C76, January 5-7, 2004 pp. 447-452.

[68] R.R. Schmidt, Local and average transfer coefficients on a vertical surface due to convection from a piezoelectric fan, InterSociety Conference on Thermal Phenomena (1994) 41-49.

[69] B.G. Loh, S. Hyun, P.I. Ro, C. Kleinstreuer, Acoustic streaming induced by ultrasonic flexural vibrations and associated enhancement of convective heat transfer, Journal of Acoustical Society of America 111 (2002) 875-883.

[70] T. Acikalin, S.V. Garimella, J. Petroski, A. Raman, Optimal Design of Miniature Piezoelectric Fans for Cooling Light Emitting Diodes Proceedings of the ITHERM04, Las Vegas, Nevada, June, 2004 pp. 663-671.

[71] P. Buermann, A. Raman, S.V. Garimella, Dynamics and topology optimization of piezoelectric fans, IEEE Transactions on Components and Packaging Technologies 25 (2002) 592-600.

[72] S. Basak, A. Raman, S.V. Garimella, Dynamic response optimization of piezoelectrically excited thin resonant beams, ASME Journal of Vibration and Acoustics 127 (2005) 18-27.

[73] F.P. Bowden, D. Tabor, The Friction and Lubrication of Solids, Oxford University Press, London, 1950, pp. 20-32.

[74] E.L. Olsen, S.V. Garimella, C.V. Madhusudana, Modeling of constriction resistance in coated joints, AIAA Journal of Thermophysics and Heat Transfer 16 (2002) 207-216.

[75] M.R. Sridhar, M.M. Yovanovich, Elastoplastic contact conductance model for isotropic, conforming rough surfaces and comparison with experiments, Journal of Heat Transfer 118 (1996) 3-9.

[76] V. Singhal, S.V. Garimella, Prediction of Thermal Contact Conductance by Surface Deformation Analysis Proceedings of the International Mechanical Engineering Congress and Exposition, New York, HTD, IMECE2001/HTD-24376, vol. 369-7 2001 pp. 43-50.

[77] V. Singhal, P.J. Litke, A.F. Black, S.V. Garimella, An experimentally validated thermo-mechanical model for the prediction of thermal contact conductance, International Journal of Heat and Mass Transfer (in press).

[78] A.F. Black, V. Singhal, S.V. Garimella, Analytical investigation and predictive correlation for constriction resistance, AIAA Journal of Thermophysics and Heat Transfer 18 (2004) 30-36.

[79] T.R. Thomas, Rough Surfaces, Imperial College Press, London, 1999, pp. 151-168. 
[80] V. Singhal, T. Siegmund, S.V. Garimella, Optimization of thermal interface materials for electronics cooling applications, IEEE Transactions on Components and Packaging Technologies 27 (2004) 244-252.

[81] P. Nika, Y. Bailly, J.C. Jeannot, M.D. Labachelerie, An integrated pulse tube refrigeration device with micro exchangers: design and experiments, International Journal of Thermal Sciences 42 (2003) 1029-1045.

[82] D. Mendoza, F. Morales, R. Escudero, Conductance of bulk samples of multiwall carbon nanotubes - metal junctions, Solid State Communications 130 (2004) 317-320.
[83] J. Xu, T.S. Fisher, Enhancement of thermal interface materials with carbon nanotube arrays, International Journal of Heat and Mass Transfer (in press).

[84] Y. Nakagiri, H. Gyoten, Y. Yamamoto, Development of film-shaped thermoelectric materials for thermoelectric modules, Applied Energy 59 (1998) 147-162.

[85] S.T. Huxtable, A. Shakouri, C. Labounty, X. Fan, P. Abraham, Y.J. Chiu, J.E. Bowers, A. Majumdar, Thermal conductivity of indium phosphide based superlattices, Microscale Thermophysical Engineering 4 (2000) 197-203. 